\title{
Como o uso de aplicativos móveis educacionais impacta o cotidiano de crianças autistas? Uma avaliação por meio de diários de usuário
}

\author{
Title: How does the use of educational mobile applications impact the daily lives of autistic \\ children? An evaluation by user's diaries
}

\author{
Karina da Silva Castelo Branco \\ Universidade Federal do Ceará \\ karinascb@alu.ufc.br \\ Adriana Lopes Damian \\ Universidade Federal do Amazonas \\ adriana@icomp.ufam.edu.br
}

\author{
Valéria Maria da Silva Pinheiro \\ Universidade Federal do Semi-Árido \\ valeria.pinheiro@alunos.ufersa.edu.br \\ Anna Beatriz dos Santos Marques \\ Universidade Federal do Ceará \\ beatriz.marques@ufc.br
}

\begin{abstract}
Resumo
O Transtorno do Espectro Autista (TEA) pode ser classificado como um tipo de transtorno global do desenvolvimento, caracterizado por prejuizos em diferentes áreas do desenvolvimento do indivíduo, como interação, socialização, concentração e principalmente na comunicação. Pesquisas relacionadas ao uso de tecnologias educacionais para o público autista no Brasil ganhou destaque após a publicação da Lei $N^{\circ} 12.674$, que institui a Política Nacional de Proteção dos Direitos da Pessoa com TEA. A vasta gama de tecnologias disponíveis e a pouca quantidade de estudos empíricos, dificulta a identificação de aplicações úteis e alinhadas aos interesses de mães, pais e profissionais que lidam com crianças autistas. Por esta razão, decidiu-se investigar sobre o uso de aplicativos educacionais móveis na aprendizagem e nas atividades diárias de crianças autistas. Para explorar a experiência de uso dos aplicativos pelas crianças em seu cotidiano, foi conduzido um estudo com o uso de diários. Os participantes do estudo foram crianças autistas cujas mães participaram de uma associação de mães do município de Jaguaruana no estado do Ceará. Os aplicativos utilizados promoveram uma boa experiência de uso, incluindo beneficios no aprendizado e desenvolvimento da comunicação. Esta pesquisa visa contribuir no contexto acadêmico e social, pois os resultados são relevantes tanto para pessoas que convivem com crianças autistas, como para profissionais da área.
\end{abstract}

Palavras-Chave: Transtorno do Espectro Autista; Aplicativos educacionais; Diários de usuário

\begin{abstract}
Autistic Spectrum Disorder (ASD) can be classified as a type of global development disorder, characterized by impairments in different areas of individual development, such as interaction, socialization, concentration, and mainly in communication. Research related to the use of educational technologies for the autistic public in Brazil gained emphasis after the publication of Law No. 12,674, which establishes the National Policy for the Rights Protection of Persons with ASD. The variety of available technologies and the few empirical studies make it difficult to identify useful applications aligned with the interests of mothers, fathers, and professionals dealing with autistic children. For this reason, we decided to investigate the use of mobile educational applications in assisting learning and daily activities of autistic children. To explore the user experience with the applications by children in their daily activities, we conducted a study with the use of diaries. The participants were autistic children whose mothers participate in a mother's association of the city Jaguaruana in Ceará state. The applications used in the study promoted a good experience for autistic children, including benefits in learning and developing communication. This research aims to contribute to the academic and social context, as the results are relevant both for people living with autistic children and for professionals.
\end{abstract}

Keywords: Autistic Spectrum Disorder; Educational apps; User Diaries

Cite as: Castelo Branco, K. S., Pinheiro, V. M. S., Damian, A. L., \& Marques, A. B. S. (2021). Como o uso de aplicativos móveis educacionais impacta o cotidiano de crianças autistas? Uma avaliação por meio de diários de usuário. Revista Brasileira de Informática na Educação, 29, 1107-1136. DOI: 10.5753/RBIE.2021.29.0.1107 


\section{Introdução}

O autismo tem sido tema de importantes debates, tanto em âmbito nacional quanto global. Com o uso de novas tecnologias, muitos autistas não verbais podem se comunicar, expressar e compartilhar suas capacidades que ficam escondidas. De acordo com a Associação Americana de Psiquiatria (APA, 2014), o Transtorno do Espectro Autista (TEA) pode ser classificado como um tipo de transtorno global do desenvolvimento, caracterizado por prejuízos em diferentes áreas do desenvolvimento do indivíduo, como interação, socialização, concentração e principalmente na comunicação. Segundo o DSM-5 (2014), o TEA é caracterizado por déficits que são considerados como transtornos sendo eles persistentes na comunicação social e na interação social em diversos contextos, incluindo déficits de socialização.

O interesse por pesquisas sobre tecnologias educacionais direcionadas ao autismo ganhou evidência após a publicação da Lei $\mathrm{N}^{\circ}$ 12.674, que institui a Política Nacional de Proteção dos Direitos da Pessoa com TEA (Gonçalves et al., 2019; Ferreira et al. 2018). No contexto internacional, a adoção de tecnologias como recursos de apoio em métodos de intervenção educacionais e terapêuticas junto às pessoas autistas é uma realidade. No Brasil, pesquisadores que conduziram revisões bibliográficas recentes sobre o tema, indicam um aumento no número de tecnologias propostas para o contexto educacional, com destaque ao público-alvo infantil e para plataformas móveis (Gonçalves et al., 2019; Ferreira et al. 2018; Silva et al., 2019).

Crianças autistas demonstram interesse em manusear e utilizar recursos computacionais como smartphone, tablet e jogos eletrônicos (Passerino et al., 2012). Sousa et al. (2019) observaram por meio de um survey com mães, pais e cuidadores de autistas sobre o uso de tecnologias de software, que as tecnologias podem promover a melhoria da comunicação, alfabetização e desenvolvimento do raciocínio lógico. Entretanto, a vasta gama de tecnologias disponíveis e a pouca quantidade de estudos empíricos, dificulta a identificação de aplicações úteis e alinhadas aos interesses de mães, pais e profissionais que lidam com crianças autistas.

Por esta razão, decidiu-se conduzir uma investigação sobre o impacto do uso de aplicativos educacionais móveis no auxílio da aprendizagem e no ensino das atividades de vida diárias (AVDs) de crianças autistas. Com o intuito de explorar a experiência de uso dos aplicativos pelas crianças em seu cotidiano, foi conduzido um estudo com o uso de diários de usuário intermediado pelas mães. Os participantes do estudo foram crianças autistas cujas mães participam de uma associação de mães de crianças autistas do município de Jaguaruana no estado do Ceará. Este estudo foi aprovado pelo Comitê de Ética em Pesquisa da Universidade Federal do Ceará, sob o CAAE n. 46356221.8.0000.5054. Esta pesquisa visa contribuir socialmente, pois investiga a relação de aplicativos educacionais para agregar valor ao ensino e auxiliar nas AVDs das crianças que possuem TEA.

O restante deste artigo está organizado da seguinte maneira: a Seção 2 apresenta a fundamentação teórica necessária para a compreensão da pesquisa. A Seção 3 apresenta os trabalhos relacionados. A metodologia adotada nesta pesquisa é descrita na Seção 4. A Seção 5 resume as principais características dos aplicativos educacionais considerados. Os resultados e discussão são apresentados na Seção 6. Por fim, a Seção 7 apresenta as conclusões e trabalhos futuros.

\section{Fundamentação Teórica}

Esta seção apresenta os conceitos necessários para auxiliar o entendimento do TEA. Além disso, os métodos e programas educacionais mais utilizados para o tratamento do TEA são apresentados. 


\subsection{Transtorno do Espectro Autista}

Esta expressão foi usada pela primeira vez por Bleuler em 1911 para designar a perda de contato com a realidade que dificultava ou até mesmo impossibilitava a comunicação (Gadia, Tuchman \& Rotta, 2004). No Brasil, o Transtorno de Espectro Autista (TEA) foi reconhecido como uma deficiência, a partir de 2012, pela Lei $\mathrm{n}^{\circ}$ 12.764/12 (Brasil, 2012). O significado do termo autismo é o de estar-se ausente ou perdido. Caracteriza-se pelo distanciamento da realidade que cerca a pessoa com o TEA, podendo apresentar um padrão de comportamentos diferentes ou não, havendo casos em que se mostram bastante diferenciados dos demais. Esse agir incomum que o afasta da realidade normal no ambiente escolar pode causar dificuldades no seu processo de interação social e acarretar consequências na aprendizagem, assimilação e acomodação dos conteúdos.

O TEA é marcado por três características fundamentais: padrão de comportamento restritivo e repetitivo; inabilidade para interagir socialmente; dificuldade no domínio da linguagem para comunicar-se (Campanário, 2008). Segundo o DSM-5 (2014) o TEA é caracterizado por déficits persistentes na comunicação social e na interação social em diversos contextos, incluindo déficits de socialização, em comportamentos não verbais, em habilidades para desenvolver, manter e compreender relacionamentos, além dos déficits na comunicação social.

Existem os graus de severidade do TEA que, segundo o DSM-5 (2014), podem ser classificados em: grau leve (Nível 1) precisa de poucos suportes para viver e desempenhar tarefas básicas; grau moderado (Nível 2) necessita apenas de alguns suportes para desempenhar tarefas básicas e possuem problemas de organização e planejamento; e grau severo (Nível 3) apresenta um déficit grave nas habilidades de comunicação verbais e não verbais, possuem um perfil inflexível de comportamento, dificuldade de lidar com mudanças, dificuldade nas interações sociais e tem cognição reduzida.

As características e sintomas apresentados em pessoas autistas, permitem mostrar a importância da utilização de tecnologias que visam proporcionar a essas pessoas mais autonomia e independência (Gonçalves et al., 2019). Além disso, o uso de treinamentos baseados em computadores tem proporcionado melhora no desenvolvimento cognitivo e nas habilidades de crianças autistas em suas atividades educacionais (Sousa, Costa \& Castro, 2012).

Dessa forma, os aplicativos, por exemplo, são apresentados como uma alternativa interessante no processo de ensino e aprendizado de pessoas autistas (Gonçalves et al., 2019). Essas ferramentas educacionais permitem a criação de um ambiente de aprendizagem estruturado e individual, muitas vezes necessário para uma criança autista possa aprender um novo conceito de forma efetiva (Ferreira et al., 2018).

\subsection{Métodos educacionais direcionados ao TEA e sua relação com aplicativos educacionais}

Ao longo dos anos, diversos tipos de intervenção foram criados para o tratamento e educação de pessoas autistas. De acordo com Mello (2007), os métodos e programas educacionais mais usuais para o tratamento do TEA são o TEACCH (Tratamento e Educação para Autistas e Crianças com Limitações), ABA (Análise Aplicada do Comportamento) e o PECS (Sistema de Comunicação Através da Troca de Figuras).

\subsubsection{Tratamento e Educação para Autistas e Crianças com Limitações}

O Método TEACCH originou-se em 1996 nos Estados Unidos, na Universidade da Carolina do Norte, na divisão de Psiquiatria da Escola de Medicina, através do Dr. Eric Schopler e outros colaboradores. O método proporciona ao autista uma forma de atendimento estruturado, visando à melhoria da qualidade de vida, dentro de um contexto familiar e social. Para Schwartzman (1995) o método TEACCH utiliza uma avaliação denominada PEP-R (Perfil Psicoeducacional 
Revisado) para avaliar a criança e determinar seus pontos fortes e de maior interesse, e suas dificuldades, a partir desses pontos, montar um programa individualizado.

O TEACCH baseia-se na organização do ambiente físico através de rotinas organizadas em quadros, agendas e sistemas de trabalho, de forma a adaptar o ambiente para torná-lo mais fácil para a criança compreendê-lo (Pantoja, Sousa \& Araújo Júnior, 2018). O TEACCH visa desenvolver a independência da criança de modo que ela necessite do professor para o aprendizado, mas que possa também passar grande parte do seu tempo ocupando-se de forma independente.

Segundo Sianlian et al. (2009), o método TEACCH pode ser utilizado em casa, na escola e no ambiente terapêutico, abordando todas as características do indivíduo em suas atividades de vida diárias, onde cada espaço tem a sua demanda específica. As crianças autistas são mais responsivas às situações dirigidas que às livres e também respondem mais consistentemente aos estímulos visuais que aos estímulos auditivos.

Na Figura 1 são apresentadas telas do aplicativo Autismo Projeto Integrar ${ }^{1}$ que adota como metodologia de ensino o TEACCH. O aplicativo tem como objetivo, ensinar aos usuários como realizar as AVDs e conta com diversas opções de atividades. Ao selecionar uma atividade o aplicativo conduz através de imagens ao passo-a-passo de como deve ser realizada.

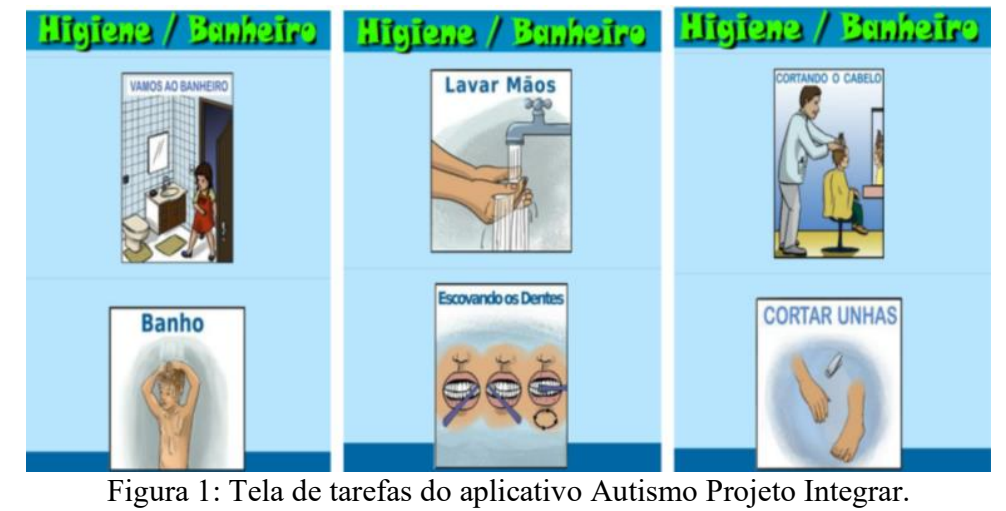

\subsubsection{Análise Aplicada do Comportamento}

$\mathrm{O}$ método ABA tem sua origem nos estudos de Skiner sobre aprendizagem e análise de comportamentos. Tal método visa trabalhar com o comportamento do autista, aumentando seu repertório de ações corretas (Serra, 2010).

Cada habilidade é ensinada individualmente, seu objetivo é fazer com que o autista desenvolva competências que o permita ser autônomo e independente (Gonçalves, 2011). Quando necessário é oferecido algum apoio que deverá ser retirado logo que seja possível, para não tornar a criança dependente do mesmo. A resposta adequada da criança tem como consequência a ocorrência de algo agradável para ela, o que na prática é uma recompensa. Quando a recompensa é utilizada de forma consistente, a criança tende a repetir a mesma resposta. O modelo ABA tem dois pontos importantes: o primeiro ponto importante está relacionado a tornar o aprendizado agradável para a criança; o segundo ponto é ensiná-la a identificar os diferentes estímulos e reações oriundos de seu aprendizado.

Na Figura 2 são apresentadas telas do aplicativo Aprendendo com Biel e seus amigos ${ }^{2}$, o qual utiliza a metodologia de ensino ABA. O aplicativo tem como objetivo ensinar diferentes habilidades, como os procedimentos de instrução para realizar os desafios, ensinar as mesmas

\footnotetext{
${ }^{1}$ https://play.google.com/store/apps/details?id=poder.ufac.br.autismoprojetointegrar

2 https://play.google.com/store/apps/details?id=com.gerenciar.desenrola
} 
habilidades funcionais em modos diferentes com os objetos do aplicativo, como: sobreposição, lado a lado e associação. Estas diferentes maneiras têm como objetivo promover o ensino de procedimentos de autocontrole dos usuários.

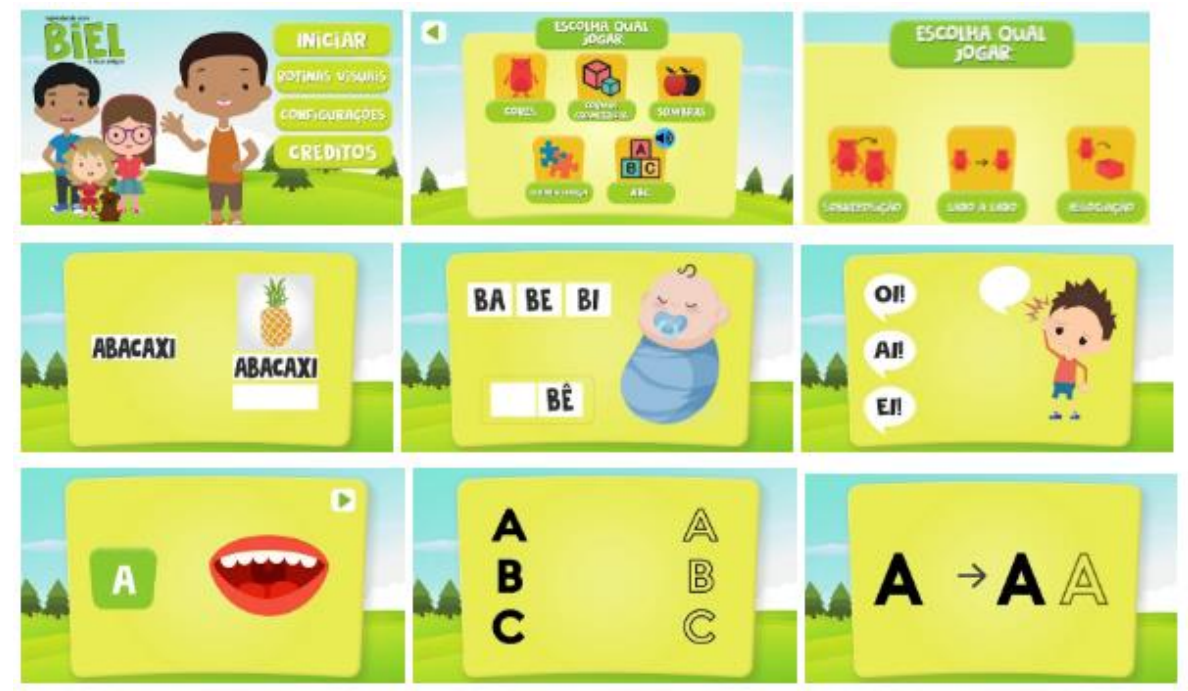

Figura 2: Tela das tarefas do aplicativo Aprendendo com Biel e seus amigos.

\subsubsection{Sistema de Comunicação Através da Troca de Figuras}

O PECS visa ajudar a criança a aprender que através da comunicação é possível conseguir muito mais rapidamente as coisas que deseja, estimulando-a assim, a comunicar-se e a diminuir problemas de comportamento. O PECS foi desenvolvido para ajudar crianças e adultos com autismo e com outros distúrbios de desenvolvimento a adquirir habilidades de comunicação (Serra, 2010).

O método PECS tem sido bem aceito em vários lugares do mundo, pois não demanda materiais complexos ou caros, sendo adotado em aplicativos como também em escolas e terapias com materiais do dia a dia. O uso pode ser aplicado em qualquer lugar, é relativamente fácil de aprender (Fernandes, 2010). Segundo Mello (2007), quando o uso do PECS é bem aplicado, o método apresenta resultados positivos na comunicação das crianças que não falam, melhora a organização da linguagem verbal, ajuda na organização da linguagem verbal em crianças que falam, mas que precisam organizar esta linguagem. O PECS se mostra eficaz em qualquer faixa etária, proporcionando situações de aprendizagem que vão além da comunicação oral e a realização de outras questões que envolvem a lógica (Gonçalves, 2011).

Na Figura 3 são apresentadas telas do aplicativo Matraquinha ${ }^{3}$, que adota a metodologia de ensino PECS. O aplicativo tem como objetivo estimular a fala do usuário através de imagens e sons. O aplicativo é dividido em categorias como: comidas, diversões, necessidades, roupas, dor, números, vogais e alfabeto. Dentro destas categorias são apresentadas ações por meio de imagens e ao clicar nas imagens, o aplicativo emite um som narrando a ação selecionada.

\footnotetext{
${ }^{3}$ https://play.google.com/store/apps/details?id=com.phonegap.matraquinha
} 


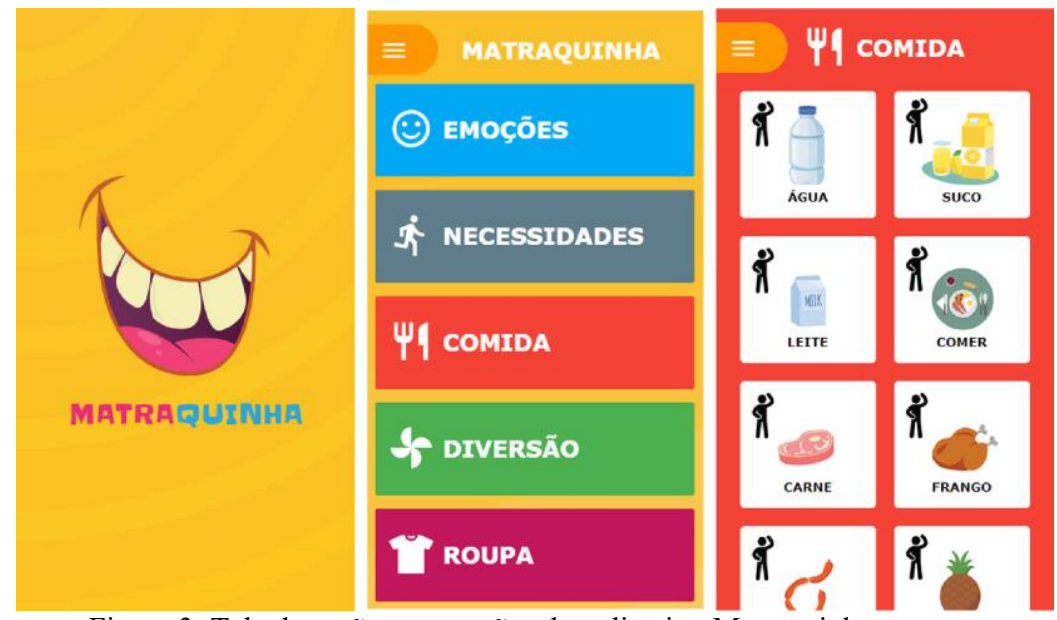

Figura 3: Tela das ações em cartões do aplicativo Matraquinha.

\section{Trabalhos Relacionados}

Pesquisas sobre processos de apoio e criação de produtos destinados a usuários autistas têm sido desenvolvidos nos últimos anos. As recentes pesquisas que relacionam o tema tecnologias digitais ao ensino de pessoas autistas apresentam diversos focos, desde a análise do uso até o desenvolvimento de novos softwares como propostas educacionais inclusivas com uso das tecnologias. Para identificar os trabalhos relacionados a esta pesquisa foram utilizadas as seguintes palavras-chaves em português: tecnologia, autismo, Transtorno do Espectro Autista e aplicativos educacionais. Uma busca foi realizada no Google Acadêmico, que indexa as publicações da Comissão Especial de Informática na Educação (CEIE-SBC). Para a seleção dos trabalhos relacionados, considerou-se os trabalhos mais recentes entre 2015 a 2019, que abordassem sobre proposição e avaliação de tecnologias com/para usuários autistas

Nas próximas seções, serão apresentados os trabalhos relacionados em duas categorias: pesquisas sobre tecnologias educacionais para usuários autistas e pesquisas que avaliam e/ou analisam o uso de tecnologias educacionais por usuários autistas.

\subsection{Pesquisas sobre tecnologias educacionais para usuários autistas}

Um estudo bibliográfico e exploratório sobre as principais ferramentas assistivas para o apoio ao ensino e aprendizagem de crianças autistas foi realizado por Gonçalves et al. (2019). Durante o estudo, os pesquisadores identificaram e catalogaram as características de 17 ferramentas identificadas. A maioria das ferramentas eram aplicativos, estavam classificadas na categoria de jogos e eram utilizadas para o auxílio na alfabetização. Os autores identificaram que a maioria das ferramentas não se adaptaram ao nível de autismo, mas levavam em consideração os aspectos relacionados aos padrões de projetos, interfaces e técnicas. Além disso, foram identificadas cinco abordagens pedagógicas para o desenvolvimento das ferramentas e a abordagem mais utilizada foi o TEACCH.

Com o objetivo de identificar e interpretar as tendências do uso de tecnologias computacionais para o ensino de crianças autistas, Silva et al. (2019) realizaram um mapeamento sistemático da literatura, cujos resultados mostraram algumas ferramentas para tal propósito. Essas ferramentas foram analisadas pelos autores em relação a: o tipo e a abordagem de ensino, as plataformas utilizadas, se a ferramenta é adaptável às necessidades da criança e se existem comparações com as metodologias tradicionais de ensino para crianças autistas. Foram identificados 218 trabalhos e a maioria dos trabalhos não utilizam abordagem de ensino como ABA, TEACCH ou PECS. Os autores relatam que $60 \%$ dos trabalhos são de uso mobile e a 
maioria dos trabalhos (87\%) não possibilita a adaptação das atividades de acordo com as necessidades da criança. Os autores concluíram que as ferramentas tecnológicas são utilizadas no processo de ensino de crianças autistas e que essas ferramentas possibilitam o apoio ao desenvolvimento no ensino de crianças com autismo.

Oliveira Neto et al. (2017) realizaram um estudo para a criação de um aplicativo móvel para auxiliar crianças autistas na realização de AVDs, levando em consideração as intervenções educacionais existentes e alguma tecnologia de apoio, que pudessem servir de base para o desenvolvimento do aplicativo. Essa ferramenta é o jogo Motivaeduc, baseado na metodologia ABA, que se destina ao desenvolvimento de habilidades e competências cognitivas. O jogo é voltado para a reabilitação e melhorias cognitivas em crianças autistas. A resposta que os autores receberam sobre o uso do aplicativo foi considerada positiva, profissionais afirmaram que o jogo poderá contribuir na vida de uma criança autistas. Essas contribuições estão ligadas ao processo de aquisição e desenvolvimento de sua autonomia, cognição e comunicação, melhorando suas relações sociais de modo que consiga viver em sociedade.

Um jogo assistivo chamado LIA foi desenvolvido por Moita et al. (2017) para facilitar o desenvolvimento de habilidades de construção de narrativas, através de métodos interativos de ensino, como o tratamento e educação para autistas e crianças com déficits (TEACCH). O jogo $L I A$ segue um fluxo de jogo contínuo e não linear, que leva o usuário a tomar decisões a cada tela e o faz produzir suas próprias narrativas. O jogo $L I A$ foi aplicado em sua versão beta para testes com três usuários autistas do sexo masculino, com faixa etária de 7 a 13 anos. A aplicação foi feita na Associação Grupo de Mães e Pais de Autistas (GMAIS), localizada na cidade de Campina Grande, Paraíba, pelos autores da pesquisa.

\subsection{Pesquisas que analisam ou avaliam softwares educacionais existentes}

Silva Neto et al. (2013) propuseram um jogo para auxiliar no processo de ensino-aprendizagem de crianças autistas. O jogo emprega a metodologia ABA como abordagem para intervenção comportamental. O jogo proposto foi $G-T E A$, com o propósito de auxiliar profissionais da área de Psicologia no ensino das cores para crianças autistas. Os autores realizaram um teste com três crianças autistas. A primeira apresentou facilidade de manusear o tablet e a cada interação com o jogo mais empolgada a criança ficava, a segunda criança apresentou dificuldades e rejeitou a utilização do tablet. Por sua vez, a terceira criança apresentou um pouco de dificuldade no início, porém conseguiu descobrir como realizar as tarefas até o final do jogo. Com isso, os pesquisadores concluíram que o jogo auxilia o profissional no ensino das cores para crianças autistas, pois desperta o interesse de aprender por meio do jogo.

Aguiar et al. (2018) avaliaram jogos digitais para pessoas autistas, sendo jogos educativos e jogos que promovem a interação social e ensino de emoções. Uma pesquisa bibliográfica foi realizada, para investigar as metodologias de ensino utilizadas com jovens autistas, como também características comuns utilizadas em jogos digitais voltados para esse público. Com o resultado desta pesquisa, um questionário foi elaborado com questões base de avaliação de jogos educativos voltados para o TEA. Nesse questionário foram investigadas as metodologias de ensino para pessoas autistas, dinâmicas e estética utilizadas em jogos para pessoas autistas. Como resultado, os autores identificaram padrões de desenvolvimento nos jogos avaliados. Com base nesses dados encontrados, os autores relataram que pretendem criar um guia para jogos digitais para pessoas autistas.

Tenório e Vasconcelos (2016) realizaram um estudo sobre como o iPad pode contribuir para o ensino de crianças autistas. Em sala de aula, a criança com autismo utiliza o iPad para as produções escritas, através do programa bloco de notas, em que se relata diariamente o que acontece fora da escola. O iPad é utilizado como uma tecnologia assistiva em consonância com os conteúdos estudados em sala de aula, fazendo com que esse recurso apoie a prática educativa, 
sendo utilizado em prol do desenvolvimento de habilidades de escrita, leitura e comunicação. $\mathrm{O}$ aplicativo foi testado com uma criança autista, com sete anos de idade, cursando o $2^{\circ}$ ano do ensino fundamental. $\mathrm{O}$ iPad trouxe uma nova forma de auxiliar o seu processo de aprendizagem de maneira mais significativa, atrativa, participativa e divertida.

Uma pesquisa sobre o uso de uma tecnologia educacional na sala de aula de Matemática, para o ensino do conteúdo de simetria em uma turma com um aluno autista foi realizada por Egido et al. (2018). Durante a aula a professora utilizou o Scratch, utilizando o jogo dos 7 erros para trabalhar a simetria. Desse modo, os autores concluíram que o uso do Scratch (Disponível no Windows, OS X, e Linux) para o ensino de simetria se mostra eficaz, pois desperta a curiosidade e incentiva o pensamento computacional, além de viabilizar a inclusão. O uso do computador permitiu que ele acompanhasse o ritmo da sala e desenvolvesse as atividades propostas acompanhado com os colegas, associado a uma proposta pedagógica significativa pode trazer grandes benefícios para alunos autistas.

\subsection{Análise dos trabalhos relacionados}

Nos trabalhos apresentados nas subseções anteriores, foi possível identificar a diversidade de metodologias que outros autores adotaram em suas pesquisas. A Tabela 1 apresenta um resumo comparativo com objetivo dos trabalhos; tipos de plataforma adotada; metodologias de ensino usadas e os tipos de tecnologias usadas.

A principal contribuição deste artigo em relação aos trabalhos relacionados está na condução de um estudo experimental com o público-alvo através do uso de quatro jogos educacionais que adotam diferentes metodologias de ensino, tais como ABA, TEACCH e PECS. Gonçalves et al. (2019) e Silva et al. (2019), por exemplo, realizaram estudos bibliográficos sobre as tecnologias adotadas para o ensino e aprendizagem de crianças autistas, identificando, por exemplo, padrões de projetos e metodologias de ensino em aplicativos móveis e desktop. Moita et al. (2017) e Oliveira Neto et al. (2017), criaram aplicativos móveis para apoiar o ensino e aprendizagem de crianças autistas com as metodologias ABA e TEACCH, respectivamente, e avaliaram os aplicativos com crianças. No entanto, tais trabalhos não focam na experiência de crianças autistas com aplicativos móveis que possuem variadas metodologias de ensino.

Tabela 1: Análise das principais características dos trabalhos relacionados em relação a esta pesquisa.

\begin{tabular}{|c|c|c|c|c|c|c|}
\hline $\mathbf{N}^{\mathbf{0}}$ & $\begin{array}{c}\text { Trabalho } \\
\text { Relacionado }\end{array}$ & $\begin{array}{c}\text { Tipo de } \\
\text { Tecnologia }\end{array}$ & Plataforma & $\begin{array}{c}\text { Tecnologia } \\
\text { Educacional }\end{array}$ & $\begin{array}{c}\text { Avaliado com } \\
\text { público-alvo }\end{array}$ & $\begin{array}{c}\text { Considera } \\
\text { AVDs }\end{array}$ \\
\hline 1 & $\begin{array}{c}\text { Gonçalves et } \\
\text { al. (2019) }\end{array}$ & $\begin{array}{c}\text { Ambiente de } \\
\text { Aprendizagem, } \\
\text { Ferramenta } \\
\text { Multimídia } \\
\text { Jogo }\end{array}$ & $\begin{array}{c}\text { Móvel/ } \\
\text { Desktop }\end{array}$ & Sim & Não & Sim \\
\hline 2 & $\begin{array}{c}\text { Silva et al. } \\
(2019)\end{array}$ & $\begin{array}{c}\text { Ferramentas } \\
\text { Nonão }\end{array}$ & $\begin{array}{c}\text { Móvel/ } \\
\text { Desktop }\end{array}$ & Sim & Não & Sim \\
\hline 3 & $\begin{array}{c}\text { Oliveira } \\
\text { Neto et al. } \\
(2017)\end{array}$ & Jogo & Móvel & Sim & Sim \\
\hline 4 & $\begin{array}{c}\text { Moita et al. } \\
(2017)\end{array}$ & Jogo & Móvel & Sim & Sim \\
\hline
\end{tabular}




\begin{tabular}{|c|c|c|c|c|c|c|}
\hline $\mathbf{N}^{\mathbf{0}}$ & $\begin{array}{c}\text { Trabalho } \\
\text { Relacionado }\end{array}$ & $\begin{array}{c}\text { Tipo de } \\
\text { Tecnologia }\end{array}$ & Plataforma & $\begin{array}{c}\text { Tecnologia } \\
\text { Educacional }\end{array}$ & $\begin{array}{c}\text { Avaliado com } \\
\text { público-alvo }\end{array}$ & $\begin{array}{c}\text { Considera } \\
\text { AVDs }\end{array}$ \\
\hline 5 & $\begin{array}{c}\text { Aguiar et al. } \\
(2018)\end{array}$ & Jogo & Não informa & Sim & Não & Não \\
\hline 6 & $\begin{array}{c}\text { Tenório e } \\
\text { Vasconcelos } \\
(2016)\end{array}$ & $\begin{array}{c}\text { Tecnologia } \\
\text { Assistiva }\end{array}$ & Ipad & Não & Sim & Sim \\
\hline 7 & $\begin{array}{c}\text { Egido et al. } \\
(2018)\end{array}$ & $\begin{array}{c}\text { Ambiente de } \\
\text { programação }\end{array}$ & Desktop & Sim & Não \\
\hline Esta pesquisa & Aplicativo & Móvel & Sim & Sim \\
\hline
\end{tabular}

\section{$4 \quad$ Metodologia}

Esta seção apresenta as atividades realizadas e os métodos adotados nesta pesquisa. A Figura 4 ilustra as etapas seguidas na condução desta pesquisa: identificação de aplicativos móveis educacionais, seleção e caracterização do público-alvo, uso de diários de usuário e análise qualitativa dos dados. Cada etapa será descrita nas subseções seguintes.

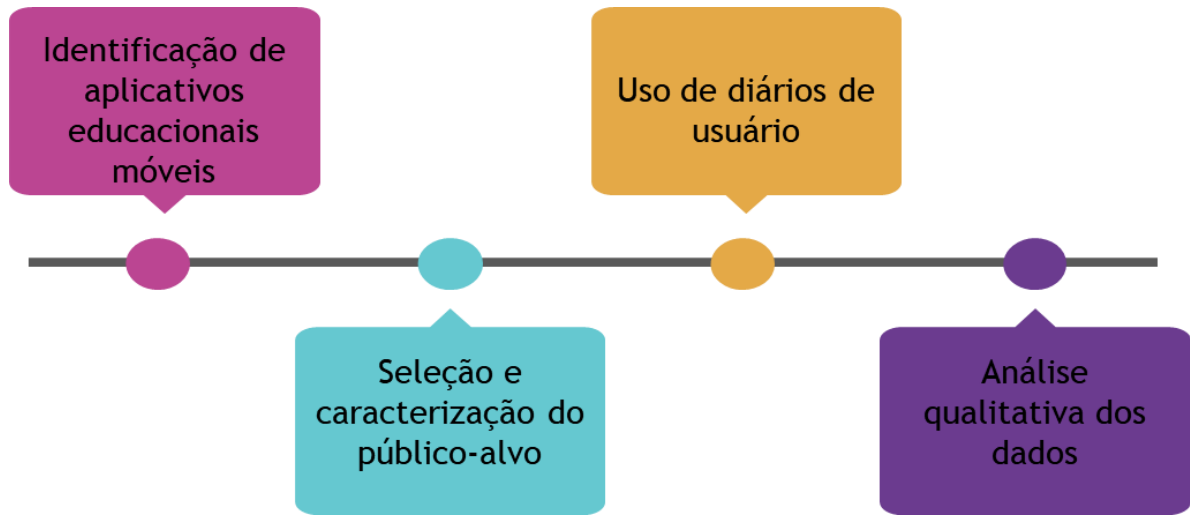

Figura 4: Etapas da metodologia de pesquisa adotada.

\subsection{Identificação de aplicativos educacionais móveis}

Com o intuito de identificar aplicativos educacionais móveis desenvolvidos para autistas e disponíveis para uso, foram realizadas pesquisas na Play Store e Google Acadêmico. Foram considerados aplicativos propostos para aprendizagem e ensino das AVDs.

Os trabalhos acadêmicos identificados no Google Acadêmico foram analisados para verificar se o aplicativo abordado estava disponível para uso. Com esta verificação, foram selecionados aplicativos com sistema operacional Android por questões de disponibilidade de dispositivos móveis para a realização da avaliação. Para cada aplicativo identificado, foi analisado: sua plataforma, se era uma tecnologia educacional e sua metodologia de ensino.

\subsection{Seleção e Caracterização do público-alvo}

O público-alvo desta pesquisa consiste em crianças autistas cujas mães participam de uma associação voltada ao autismo, no município de Jaguaruana. O contato com as mães foi viabilizado pela organizadora da associação e iniciado por meio de um grupo de Whatsapp. No 
primeiro contato com as mães, a pesquisadora principal deste trabalho apresentou-se e explicou o objetivo da pesquisa, convidando as mães para um primeiro contato presencial com objetivo de apresentar os detalhes da pesquisa. Todas as dez mães aceitaram o convite.

No primeiro contato presencial entre a pesquisadora principal e as mães, foi realizada uma palestra. A palestra ocorreu em maio de 2019, na escola Francisco Jaguaribe que disponibilizou o ambiente para a condução desta etapa da pesquisa. A palestra tinha como objetivo explicar as etapas da pesquisa, apresentar os aplicativos educacionais identificados, entregar uma ficha para a escolha dos aplicativos a serem avaliados, apresentar o Termo de Consentimento Livre e Esclarecido (TCLE) para esclarecer a pesquisa e garantir a participação voluntária e aplicar um questionário de caracterização do público-alvo. O TCLE pode ser acessado pelo link $<$ https://doi.org/10.6084/m9.figshare.14470761.v1>.

Decidiu-se fornecer às mães a possibilidade de escolher os aplicativos de seu interesse, para promover uma maior motivação no uso dos aplicativos educacionais. O questionário de caracterização foi organizado em algumas seções, como: caracterização do perfil (idade, gênero, ano escolar), sobre o TEA (nível de autismo, diagnóstico, aspectos negativos do autismo), o uso de tecnologias (plataforma, conteúdos) pelas crianças e frequência de uso, percepção sobre o apoio de tecnologias. A Figura 5 resume as informações coletadas.

Em relação ao gênero das crianças, nove crianças eram do gênero masculino e somente uma criança era do gênero feminino. Três crianças tinham 3 anos de idade, cinco crianças tinham 4 anos de idade, uma criança tinha 6 anos de idade e uma criança tinha 7 anos de idade. Todas as crianças frequentavam a escola e possuíam o diagnóstico médico do autismo. Sobre o nível de autismo, oito crianças possuem o diagnóstico de autismo leve e duas crianças possuem o diagnóstico de autismo moderado. Nenhuma das crianças participantes desta pesquisa possuem o diagnóstico de autismo severo. Todas as crianças eram autistas verbais, ou seja, se comunicavam por meio da fala.

Considerando a experiência das crianças com tecnologia, todas as crianças utilizam tecnologia em seu cotidiano. Sete crianças utilizam tecnologia frequentemente e três crianças utilizam sempre. Dentre as tecnologias utilizadas, oito crianças utilizam smartphone, uma utiliza tablet e uma outra criança utiliza computador. Os tipos de conteúdo mais acessados são vídeos e jogos.

Analisando a percepção das mães sobre o uso de tecnologias por pessoas autistas, observou-se que todas as mães concordam (fortemente ou não) que o uso de tecnologias pode apoiar o cotidiano, o ensino, a aprendizagem e o desenvolvimento de pessoas autistas. Duas mães nem concordam, nem discordam que existem tecnologias adequadas para pessoas autistas, enquanto oito mães concordam que existem. Sete mães discordaram (fortemente ou não) que o uso de tecnologias prejudica a socialização de pessoas autistas.

\subsection{Uso de diários de usuário}

Considerando o contexto de uso dos aplicativos educacionais, observou-se que uma única sessão de teste com os usuários poderia não fornecer um resultado relevante para esta pesquisa. Assim, decidiu-se selecionar um método que acompanhasse a experiência do usuário por um determinado tempo de uso. Por esse motivo, foi adotado o diário de usuário para compreender os sentimentos, experiências e obter relatos de uso de tecnologias (Lazar et al., 2017). 


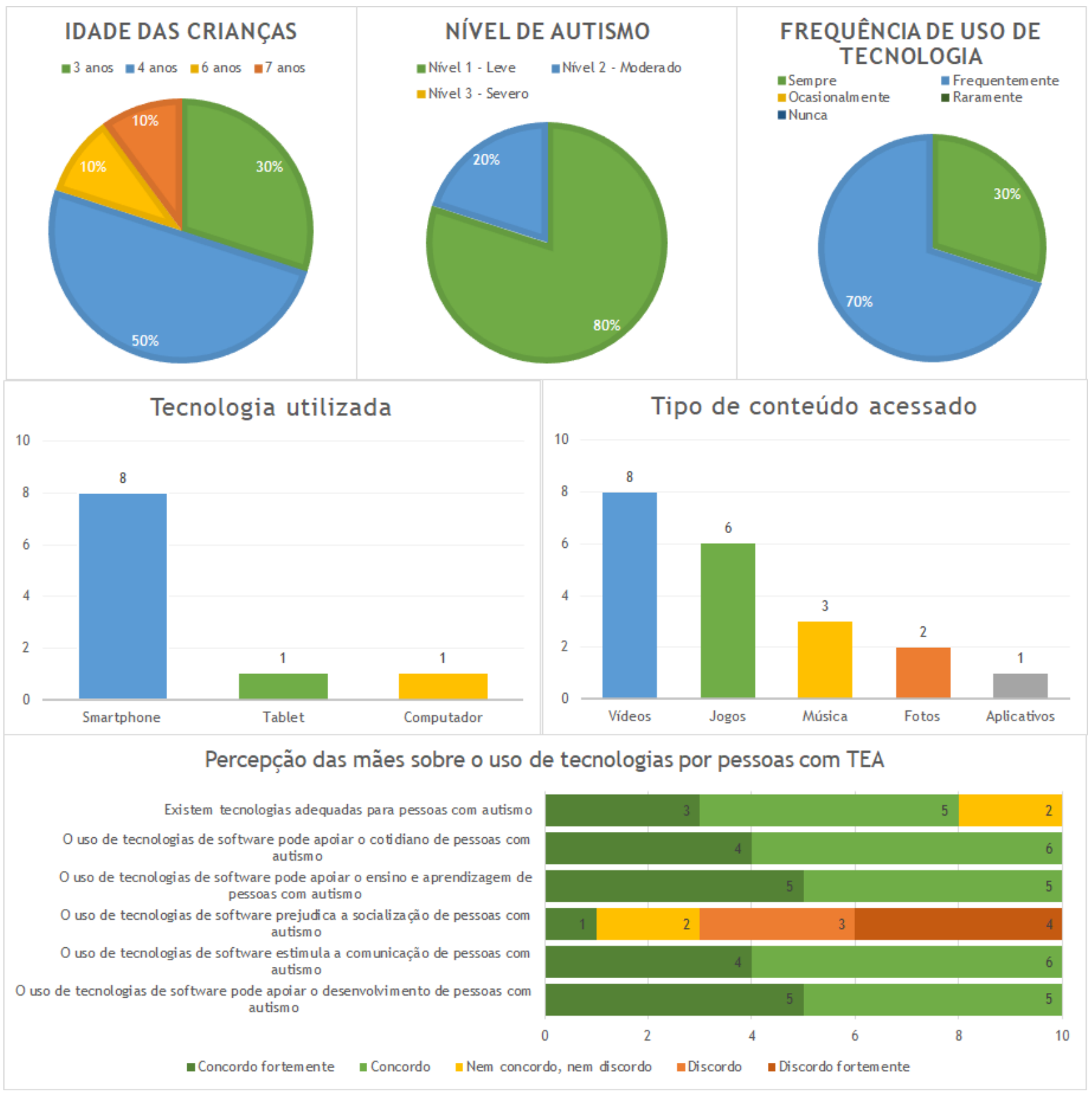

Figura 5: Gráficos da caracterização dos participantes da pesquisa.

Um diário é um documento criado por um indivíduo que mantém anotações regulares sobre eventos de suas vidas, enquanto eles ocorrem (Zaccarelli, 2010). Os diários possibilitam preencher as lacunas dos outros métodos desta pesquisa, como a observação em cenários naturalistas ou a observação em um laboratório fixo (Hyldegard, 2006). Nesta pesquisa, a metodologia de diário é essencial para uma análise do desempenho e engajamento de cada criança com os aplicativos educacionais utilizados e para averiguar as contribuições de cada aplicativo, identificar possíveis dificuldades, reações e emoções oriundos do seu uso contínuo.

O método de diário de usuário foi utilizado nesta pesquisa especialmente para avaliar aspectos da experiência de uso dos participantes em relação aos aplicativos educacionais escolhidos pelas mães. O diário foi adotado no período de duas semanas, conforme recomendado por Lazar et al. (2017). Uma estrutura de relato foi fornecida para as mães, de modo a garantir que as informações de interesse da pesquisa fossem obtidas. O relato deveria seguir a seguinte estrutura: qual aplicativo a criança estava usando; se a iniciativa de uso foi da criança ou da mãe; o tempo médio de uso; se a criança manteve atenção ao usar o aplicativo; se houve problema 
durante o uso do aplicativo; relatar como foi a experiência de uso; se houve alteração de humor durante o uso; se alguma mudança no comportamento da criança foi observada.

Os relatos foram fornecidos pelas mães dos participantes da pesquisa diariamente. Para facilitar a coleta de dados, as mães poderiam produzir áudios ou mensagens de texto com os relatos e enviá-los para a pesquisadora principal pelo Whatsapp. As mães ficaram responsáveis por incentivar, observar e relatar o uso dos aplicativos ao longo das duas semanas. A frequência de registro é algo muito importante no armazenamento de um diário. Então, para que as mães não esquecessem do registro, foi pré-estabelecido pela pesquisadora o envio de mensagem diariamente no grupo da pesquisa lembrando sobre a importância dos relatos.

\subsection{Análise qualitativa dos dados}

A pesquisa qualitativa está direcionada a coletar e analisar dados não numéricos com o objetivo de alcançar a profundidade da informação ao invés de largura (Barbosa, 2017). Uma vez que os dados coletados por meio dos diários de usuário são qualitativos, decidiu-se conduzir uma análise qualitativa sobre os dados com o apoio do método Grounded Theory (Strauss e Corbin, 2014). O Grounded Theory (GT) fornece um procedimento rigoroso para explorar um domínio, com ênfase na descoberta de novos conhecimentos e na construção de entendimentos parciais sobre uma teoria mais ampla do domínio (Muller, 2014). Essa teoria emerge dos dados, ou seja, é uma teoria derivada de dados sistematicamente coletados e analisados. De acordo com Strauss e Corbin (2014), GT é baseada na ideia de codificação, que é o processo de analisar os dados. Nesta codificação, estão envolvidos os procedimentos de:

Codificação aberta: consiste na codificação, ou seja, um processo de associar trechos a códigos e categorias. Um código dá nome a um fenômeno de interesse para o pesquisador, podendo ser um evento, ação, reação, interação que possui um significado importante para a pesquisa em questão. A codificação aberta tem como característica a análise, a comparação e a categorização dos dados obtidos de acordo com a percepção do pesquisador.

Codificação axial: consiste em identificar relacionamentos entre os códigos identificados na codificação aberta e criar categorias que podem relacionar diferentes códigos.

Codificação seletiva: refina todo o processo identificando a categoria central da teoria, com a qual todas as outras estão relacionadas. Tal categoria pode ser uma categoria existente, ou uma nova categoria pode ser criada.

Embora a finalidade do método GT seja a construção de teorias substantivas, segundo Strauss e Corbin (2014), o pesquisador pode usar apenas alguns de seus procedimentos para satisfazer seus objetivos de pesquisa. Por essa razão, como não se pretendia criar uma teoria sobre a experiência das crianças com os aplicativos, a codificação aberta e a codificação axial foram suficientes para a análise dos dados.

\section{$5 \quad$ Aplicativos educacionais avaliados}

A Tabela 2 resume as principais características dos aplicativos educacionais identificados pelas pesquisadoras envolvidas. Os aplicativos educacionais avaliados nesta pesquisa, conforme o interesse das mães participantes, são detalhados nas subseções seguintes. 
Tabela 2: Comparativo entre os aplicativos educacionais identificados.

\begin{tabular}{|c|c|c|c|}
\hline Aplicativo & Plataforma & Método educacional & Hiperlink \\
\hline Autismo projeto integrar & Móvel & TEACCH & $\begin{array}{c}\text { https://play.google.com/store/a } \\
\text { pps/details?id=poder.ufac.br.au } \\
\text { tismoprojetointegrar\&hl=pt_B } \\
\text { R }\end{array}$ \\
\hline $\begin{array}{l}\text { Aprendendo com Biel e seus } \\
\text { amigos }\end{array}$ & Móvel & $\mathrm{ABA}$ & $\begin{array}{l}\text { https://play.google.com/store/a } \\
\text { pps/details?id=com.gerenciar.d } \\
\text { esenrola\&hl=pt_BR }\end{array}$ \\
\hline $\mathrm{ABC}$ autismo & Móvel/Desktop & TEACCH & $\begin{array}{c}\text { https://play.google.com/store/a } \\
\text { pps/details?id=com.dokye.abca } \\
\text { utismo\&hl=pt_BR }\end{array}$ \\
\hline Jade autismo & Móvel & ABA/TEACCH & $\begin{array}{l}\text { https://play.google.com/store/a } \\
\text { pps/details?id=com.jadeautism. } \\
\text { jadeautism\&hl=pt_BR }\end{array}$ \\
\hline Matraquinha & Móvel & PECS & $\begin{array}{l}\text { https://play.google.com/store/a } \\
\text { pps/details?id=com.phonegap. } \\
\text { matraquinha\&hl=pt_BR }\end{array}$ \\
\hline OTO (Olhar, Tocar, Ouvir) & Móvel & PECS & $\begin{array}{c}\text { https://play.google.com/store/a } \\
\text { pps/details?id=br.com.myalpha } \\
\text { beto\&hl=pt_BR }\end{array}$ \\
\hline Teacch.me & Móvel & TEACCH & $\begin{array}{l}\text { https://play.google.com/store/a } \\
\text { pps/details?id=appinventor.ai_ } \\
\text { maratonadeapp.TeacchME11\& } \\
\text { hl=pt_BR }\end{array}$ \\
\hline
\end{tabular}

\subsection{ABC Autismo}

A principal função deste aplicativo é auxiliar no processo de alfabetização e servir como ferramenta de apoio no tratamento e educação de crianças e adolescentes autistas. $\mathrm{O}$ aplicativo $A B C$ Autismo (Figura 6) é baseado na metodologia TEACCH, possui 40 fases interativas distribuídas em 04 níveis de dificuldade. Cada nível de dificuldade corresponde a um nível de trabalho TEACCH e suas fases tratam a atividade de transpor figuras de uma área denominada Área de Armazenamento (metade esquerda da tela), até uma área denominada Área de Execução (metade direita da tela).

Diversas características do método TEACCH foram implementadas no aplicativo $A B C$ Autismo, entre elas, podemos destacar a ordem crescente de nível, a diferenciação entre tamanhos, formas e cores dos objetos representados (Farias; Silva; Cunha, 2014). O aplicativo foi desenvolvido por pesquisadores do Instituto Federal de Alagoas (IFAL). A coordenadora do projeto que desenvolveu o aplicativo, Mônica Ximenes. 


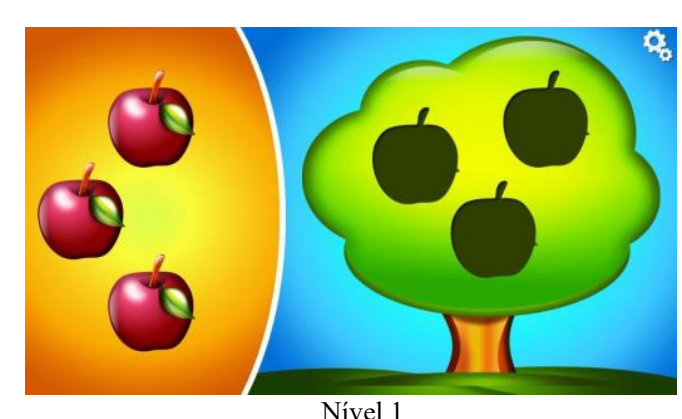

Nível 1

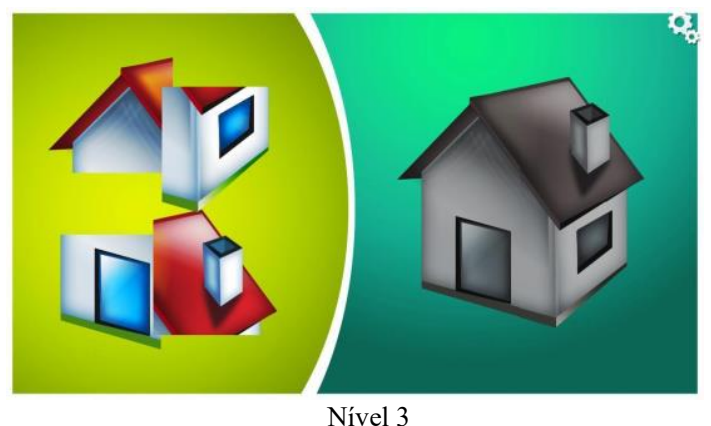

Nível 3

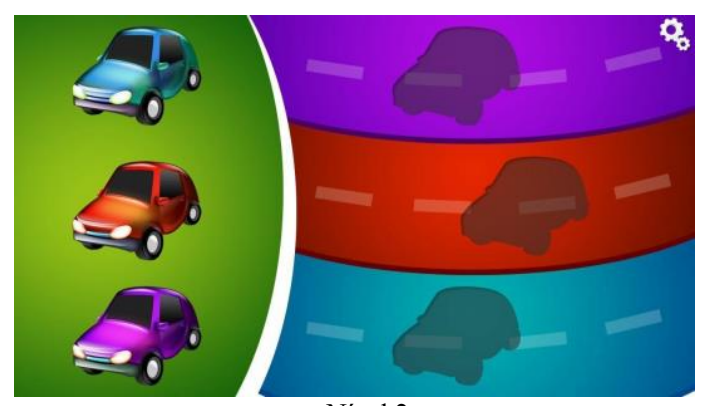

Nível 2

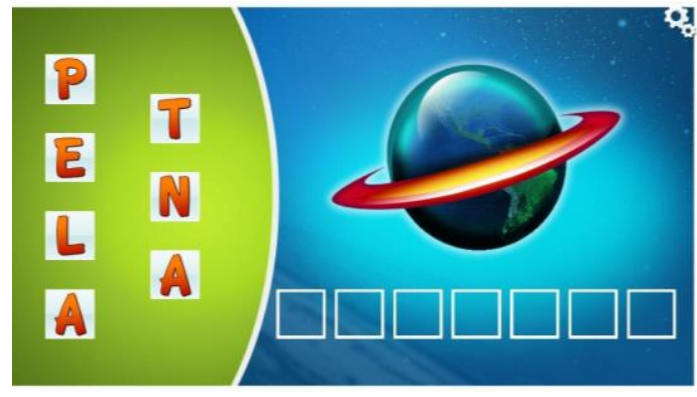

Nível 4

Figura 6: Os quatro níveis do aplicativo ABC do autismo - Adaptado de Farias, Silva e Cunha (2014).

\subsection{OTO (Olhar, Tocar, Ouvir)}

O objetivo geral deste aplicativo é ensinar o alfabeto de uma forma lúdica, interativa e autônoma, através de associações de imagens e sons, desenvolvidos como uma ferramenta educacional para auxiliar crianças em diferentes níveis do TEA (Rodrigues; Abilhoa, 2015). O aplicativo OTO (Figura 7) é baseado na metodologia PECS e consiste de um conjunto de imagens que representam as letras do alfabeto.

Nesse contexto, ao tocar sobre uma dessas letras, um som de fundo é apresentado dizendo qual letra foi selecionada e em seguida é exibida a figura de um animal ou objeto junto com um som dizendo qual é a figura exibida, permitindo a associação entre a letra e a figura, permitindo maior percepção e engajamento por parte das crianças. Este aplicativo é o trabalho de conclusão de curso do aluno Jesher Heliel Rodrigues. O aplicativo foi testado na Associação dos Amigos dos Autistas (AMA), em Maringá, no estado do Paraná.

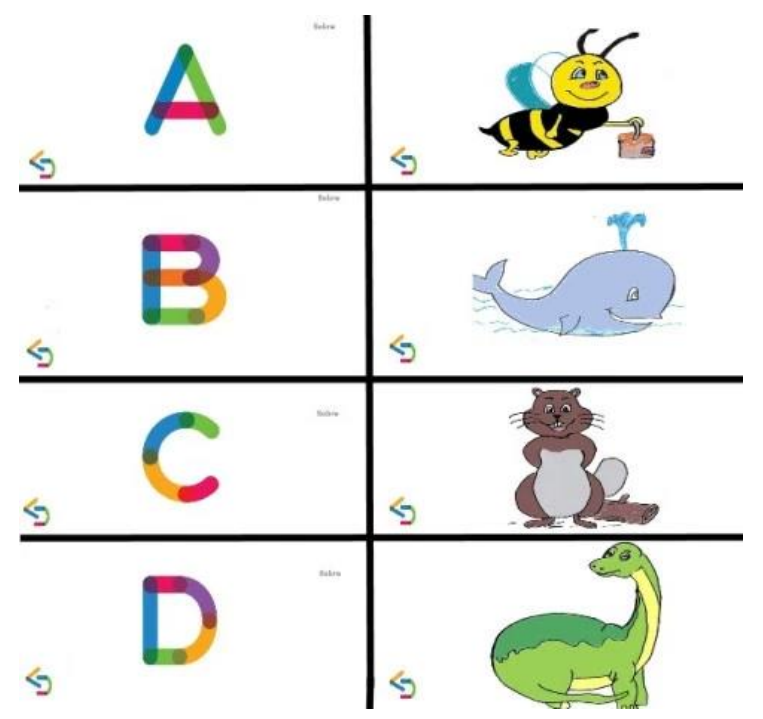

Figura 7: Tela inicial do aplicativo OTO (Rodrigues e Abilhoa, 2015). 


\subsection{Jade Autismo}

O Jade Autismo 4 é um aplicativo para estímulo e desenvolvimento de crianças autistas e com Síndrome de Down. O Jade (Figura 8) é baseado na metodologia ABA e Teacch, o aplicativo conta com diversas categorias que estimulam o desenvolvimento cognitivo, a memória, o raciocínio, a habilidade e o desempenho, além de gerar relatórios diante o desempenho da criança durante o jogo, apresentando dados valiosos para que possam ser avaliados posteriormente. No geral cada categoria tem como objetivo que a criança encontre respostas e trabalham de maneiras diferente um mesmo desafio com associações entre: Animais, Alimentos, Cores, Números e Formas.
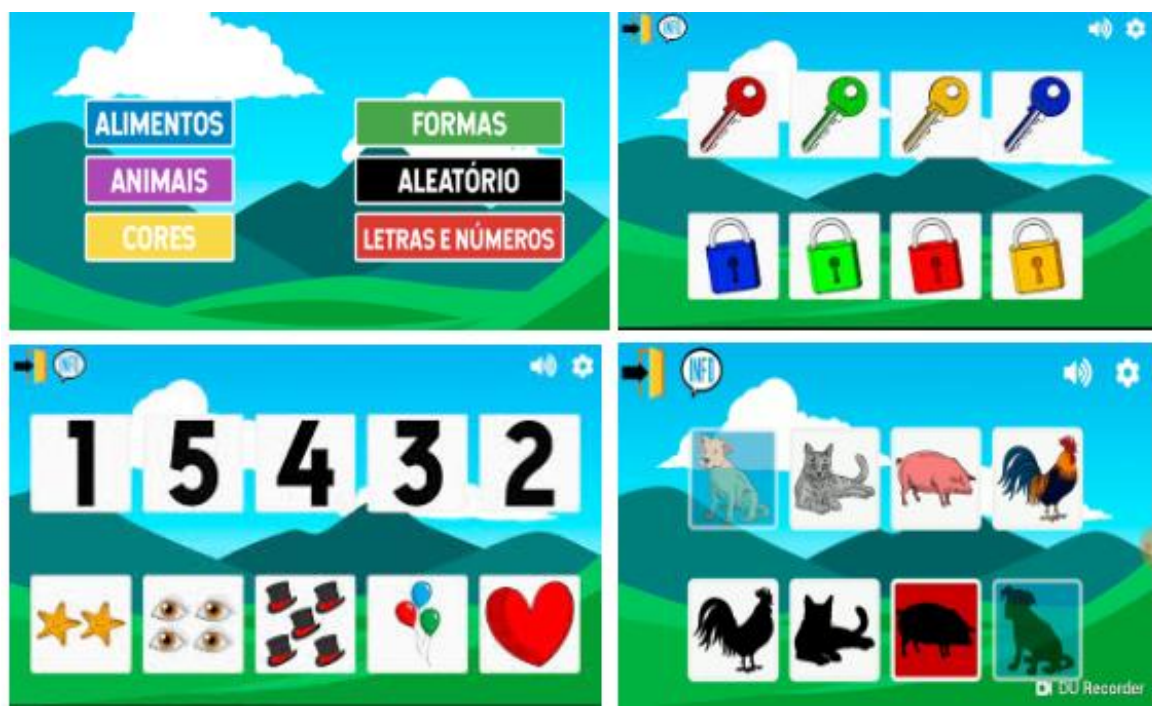

Figura 8: Telas do aplicativo Jade Autismo.

As imagens apresentadas neste aplicativo ilustram a seleção: primeiro o usuário deverá escolher uma imagem acima e clicar. Em seguida procurar dentre as outras opções a mesma imagem e clicar novamente para realizar a ação. Um aplicativo simples e bem intuitivo. Este aplicativo foi desenvolvido por Ronald Cohin, pai de uma criança autista.

\subsection{Aprendendo com Biel e seus amigos}

Jogo desenvolvido pela empresa Gerenciar Sistemas Corporativos para crianças com autismo e com outros atrasos no desenvolvimento cognitivo e verbal. O aplicativo educacional (Figura 9) adota a metodologia $\mathrm{ABA}$, tentando estimular o raciocínio lógico dos usuários, trabalhando diversos desafios de maneiras diferente, o objetivo é facilitar o aprendizado e interação da criança em seu dia a dia. Para cada categoria do aplicativo existem 3 opções diferentes para utilizar metodologias diferentes como: sombreamento; associação e lado a lado. O aplicativo foi desenvolvido e discutido em conjunto com os pais de uma criança autista e uma equipe multidisciplinar (psicopedagogo, fonoaudiólogo, terapeuta ocupacional).

\footnotetext{
${ }^{4}$ https://play.google.com/store/apps/details?id=com.jadeautism.jadeautism
} 

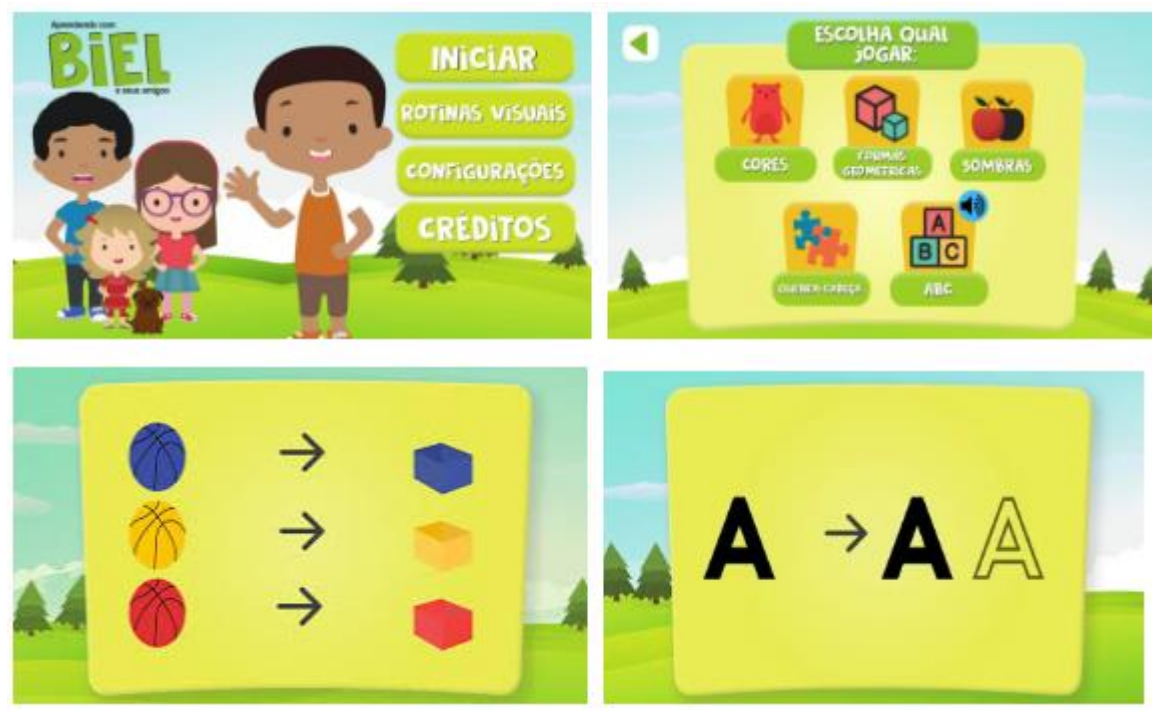

Figura 9: Telas do aplicativo Aprendendo com Biel e seus amigos.

\section{$6 \quad$ Resultados}

Nesta seção serão apresentados os resultados da seleção dos aplicativos pelas mães e da análise qualitativa dos dados obtidos por meio do diário de usuário.

\subsection{Preferência das mães em relação aos aplicativos educacionais}

Os resultados obtidos nesta subseção foram coletados por meio de questionários aplicados após a palestra de apresentação da pesquisa. Os questionários foram respondidos pelas mães das crianças participantes do estudo. Segundo as mães, nenhuma das crianças participantes possuía experiência prévia com os aplicativos educacionais apresentados.

As mães poderiam indicar o interesse em experimentar um ou mais aplicativos educacionais. O aplicativo ABC Autismo foi selecionado por todas as mães, enquanto Jade Autismo foi selecionado por nove mães. Cinco mães selecionaram Aprendendo com Biel e seus amigos e três mães selecionaram OTO (Olhar, Tocar, Ouvir). Nenhuma mãe selecionou os aplicativos Autismo projeto integrar, Matraquinha, AutApp e Teachh.me. Assim, os aplicativos não selecionados não foram avaliados nesta pesquisa, pois somente os aplicativos de interesse das mães foram utilizados. A Tabela 3 indica os participantes que experimentaram cada aplicativo, segundo o interesse das mães.

Tabela 3: Resumo de participantes e aplicativos avaliados.

\begin{tabular}{|c|c|c|c|c|c|c|}
\hline $\begin{array}{c}\text { ID da } \\
\text { criança }\end{array}$ & $\begin{array}{c}\text { Nível de } \\
\text { autismo }\end{array}$ & $\begin{array}{c}\text { Idade da } \\
\text { criança }\end{array}$ & $\begin{array}{c}\text { ABC } \\
\text { Autismo }\end{array}$ & $\begin{array}{c}\text { Jade } \\
\text { Autismo }\end{array}$ & $\begin{array}{c}\text { Aprendendo } \\
\text { com Biel e seus } \\
\text { amigos }\end{array}$ & OTO \\
\hline P1 & Nível 1 & 4 anos & $\mathrm{X}$ & $\mathrm{X}$ & & $\mathrm{X}$ \\
\hline P2 & Nível 2 & 4 anos & $\mathrm{X}$ & $\mathrm{X}$ & & \\
\hline P3 & Nível 1 & 3 anos & $\mathrm{X}$ & $\mathrm{X}$ & $\mathrm{X}$ & \\
\hline
\end{tabular}




\begin{tabular}{|c|c|c|c|c|c|c|}
\hline $\begin{array}{c}\text { ID da } \\
\text { criança }\end{array}$ & $\begin{array}{c}\text { Nível de } \\
\text { autismo }\end{array}$ & $\begin{array}{c}\text { Idade da } \\
\text { criança }\end{array}$ & $\begin{array}{c}\text { ABC } \\
\text { Autismo }\end{array}$ & $\begin{array}{c}\text { Jade } \\
\text { Autismo }\end{array}$ & $\begin{array}{c}\text { Aprendendo } \\
\text { com Biel e seus } \\
\text { amigos }\end{array}$ & OTO \\
\hline P4 & Nível 1 & 4 anos & X & X & X \\
\hline P5 & Nível 1 & 4 anos & X & X & X \\
\hline P6 & Nível 1 & 4 anos & X & X & X \\
\hline P7 & Nível 1 & 7 anos & X & X & X \\
\hline P8 & Nível 1 & 3 anos & X & X & \\
\hline P9 & Nível 2 & 3 anos & X & & & \\
\hline
\end{tabular}

"X" - indica que o aplicativo foi selecionado pela mãe responsável pela criança

\subsection{Experiência com o uso dos aplicativos}

A Figura 10 ilustra os passos adotados para a execução e validação da análise qualitativa dos dados. Tais passos foram conduzidos da seguinte maneira:

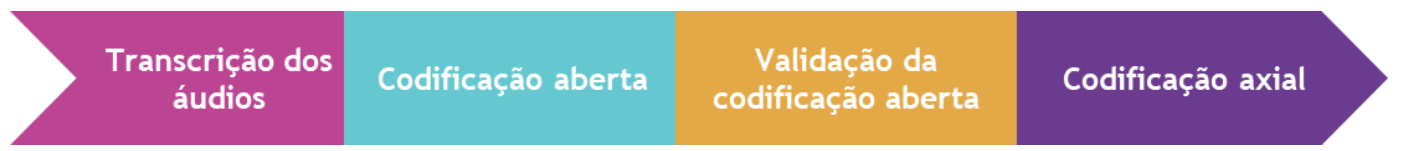

Figura 10: Passos adotados na análise qualitativa.

Transcrição dos áudios: inicialmente a pesquisadora transcreveu todos os áudios de relatos recebidos. Como o diário foi adotado durante duas semanas, foi definido que cada mãe deveria ter enviado dez áudios. Todas as mães enviaram os áudios corretamente e diariamente, exceto uma que enviou oito relatos. Porém, decidiu-se não descartar os relatos enviados por essa mãe, pois a mesma justificou a ausência dos áudios devido à severidade do autismo de seu filho.

Codificação aberta: após a transcrição dos áudios, a pesquisadora responsável realizou a codificação aberta com o auxílio da ferramenta ATLAS.ti ${ }^{5}$.

Validação da codificação aberta: para validar se os códigos criados pela pesquisadora responsável de fato refletiam os trechos transcritos, todos os códigos foram revisados por uma segunda pesquisadora que possui experiência na execução de análise qualitativa com GT. A validação ocorreu ao longo de duas reuniões com duração média de uma hora cada. Nesta etapa, alguns códigos foram renomeados para melhor representar o conteúdo dos trechos codificados.

Codificação axial: Esta etapa foi realizada em conjunto pela pesquisadora responsável e a segunda pesquisadora que validou a codificação aberta. Os esquemas gráficos obtidos pelo ATLAS.ti para representar a codificação axial serão utilizados para apresentar e discutir os

\footnotetext{
5 https://atlasti.com/
} 
resultados desta pesquisa nas próximas subseções. Além disso, os trechos transcritos que geraram os códigos serão apresentados.

\subsubsection{ABC do Autismo}

Os relatos das dez mães em relação ao uso do aplicativo $A B C$ autismo por seus filhos indicaram algumas questões mediante suas observações no período de duas semanas. Na etapa de codificação aberta, foram criados os códigos: (i) Promove boas experiências, (ii) Falta de variedade nos desafios, (iii) Uso excessivo, (iv) Dificuldade de acessibilidade/interação, (v) Irritação quando não consegue concluir os desafios e (vi) Auxilia na coordenação motora. Por meio da codificação axial, decidiu-se criar a categoria Percepções das Mães sobre ABC Autismo para relacionar os códigos identificados na codificação aberta.

A Figura 11 representa o esquema gráfico obtido a partir do relacionamento dos códigos e categorias relacionados ao aplicativo ABC Autismo. Cada código possui dois valores: grau de fundamentação teórica, que indica o número de vezes que o código emergiu dos dados qualitativos, ou seja, a quantos diferentes trechos o código está relacionado; e grau de densidade teórica, que indica a quantos códigos ou categorias está relacionado. Geralmente, as categorias possuem grau de fundamentação teórica igual a zero, por terem sido criadas pelo pesquisador para relacionar dois ou mais códigos. Códigos com borda na cor vermelha indicam percepções negativas sobre o aplicativo, enquanto códigos com borda verde indicam percepções positivas.

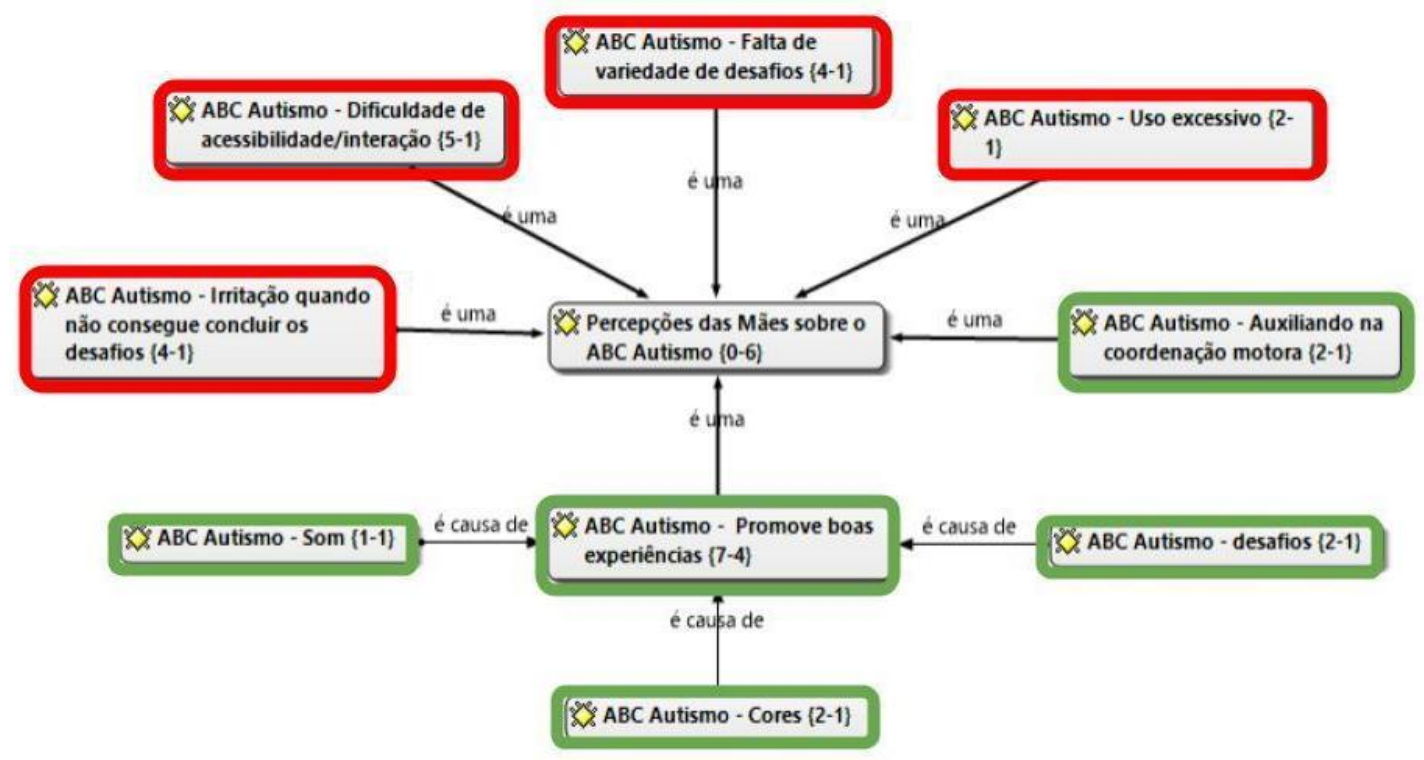

Figura 11: Codificação dos dados do aplicativo ABC Autismo.

ABC Autismo - Auxilia na coordenação motora: representam os relatos das mães que indicam a relação do $A B C$ Autismo no apoio à coordenação motora das crianças autistas como, por exemplo, nos relatos de P1 e P2:

P1 (Nível leve) - "O ABC do autismo todos os dias ele joga uns 10 minutos e vejo como ele está melhorando a coordenação motora”.

P2 (Nível moderado) - "O ABC Autismo eu vejo que está melhorando a coordenação motora dele"

ABC Autismo - Irritação quando não consegue concluir os desafios: apresentam os relatos das mães que indicam que as crianças demonstraram irritação em relação a não conseguir concluir os desafios do aplicativo como: 
P1 (Nível leve) - “[...] mas ele só quis aquele joguinho que tem as quatro fases (ABC Autismo), ele consegue jogar sozinho até a fase 3, mas quando chega na fase 4 para completar as palavras ele não consegue e se irrita". A Figura 12 ilustra exemplos de desafios da fase 4 do ABC Autismo.

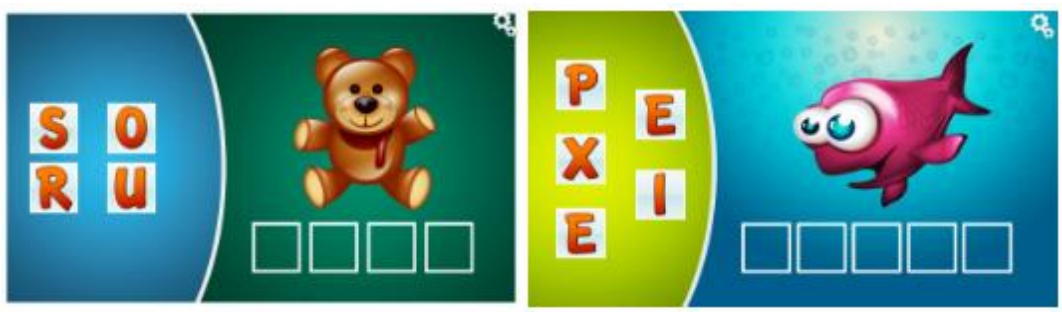

Figura 12: Desafios da fase 4 do aplicativo ABC Autismo

P4 (Nível leve) - “[...] hoje houve um pouco de estresse quando ela estava jogando e não estava conseguindo montar o quebra cabeça do ABC Autismo”.

P6 (Nível leve)- "Hoje ele jogou o ABC Autismo, ela se distrai fácil, fica clicando em outros ícones da tela e o humor dela muda quando erra alguma atividade, ela fica brava".

ABC Autismo - Dificuldade com acessibilidade/interação: as crianças demonstraram dificuldades de acessibilidade/interação durante o uso do aplicativo como:

P2 (Nível moderado)- "[ele] não tem muita coordenação na mão, e como tem que segurar a bola e arrastar até o final sem soltar, quando chega no meio [do percurso], ele solta, ai tem que voltar do início e fazer tudo de novo. Isso irrita ele.” A Figura 13 exemplifica a interação relatada por P2, a área para arrastar e soltar dificulta a interação para crianças com coordenação motora limitada.

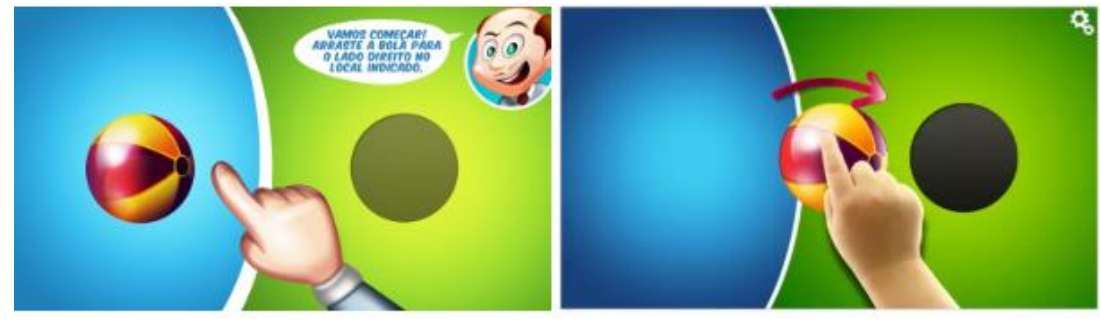

Figura 13: Desafios da fase 1 do aplicativo ABC Autismo

P10 (Nível leve) - "ele jogou o ABC Autismo até a fase 3 sem pedir ajuda, na fase 4 ele ficou me chamando pra ajudar ele sente muita dificuldade”.

P1 (Nível leve) - "O jogo mostra a figura e apresenta as opções das letras, mas ele não sabe montar, ele sabe o que é a figura". A Figura 14 ilustra desafios relacionados à experiência relatada por P1 e P10. É possível destacar a ausência de orientações sobre como realizar os desafios. 


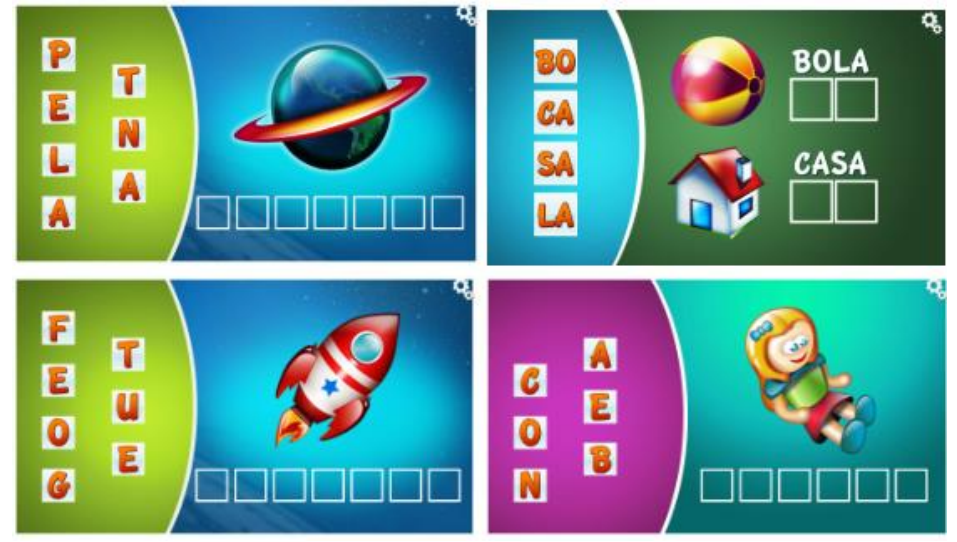

Figura 14: Exemplos de desafios da fase 4 do aplicativo ABC Autismo

ABC Autismo - Uso excessivo: apresentam os relatos das mães que indicam que as crianças apresentaram um uso excessivo do aplicativo, como:

P5 (Nível leve) - "[ele] preferiu ficar jogando o ABC autismo, ficou uns 10 minutos nesse jogo, ai eu disse 'não vai querer jogar nos outros?' ele disse 'já já mamãe, esse é mais legal'. Ele não quer parar de jogar, quando terminam as fases ele volta para a primeira [fase] de novo. Peço o celular e ele não quer me devolver, não sei dizer se isso é bom ou ruim porque é como se tivesse virando um vício".

P10 (Nível leve) - "Hoje ele mesmo pegou o meu celular e colocou no ABC [autismo]. Se eu não pedir o celular, ele não pára [de jogar], igual como ele fez na primeira semana. Às vezes acho que pode se tornar um vício pra ele"

ABC Autismo - Falta de variedades nos desafios: apresentam os relatos das mães que indicam que o aplicativo possui falta de variedade de desafios, como:

P1 (Nível leve) - "[ele] joga no máximo 5 minutos e depois não quer mais porque é sempre as mesmas coisas e ele acaba decorando como fazer".

P2 (Nível moderado) - “O ABC Autismo ele só consegue ir até a fase 3. É muita coisa repetida nesse jogo viu, [ele] não gosta acaba decorando".

P6 (Nível leve) - "[ele] teve iniciativa agora a tarde, jogou o ABC [Autismo] uns 8 minutos só. Ele só jogou até a fase 2, ele enjoa rápido porque são muitas fases dentro de um nível com as mesmas coisas".

P7 (Nível leve) - “[ele] começou jogando ABC [autismo], mas ele não segue a ordem das fases, ele fala que é fácil e vai pulando. Ele gosta da fase 4 que é para montar as palavras e como isso requer mais tempo para pensar, [então] ele gosta. As outras fases são muito simples, mesmas coisas mudando só os objetos, mas a ação é sempre a mesma".

ABC Autismo - Promove boas experiências: indicam a relação do ABC Autismo em promover boas experiências a crianças autistas. Foi possível identificar que as boas experiências são proporcionadas pelos desafios, cores e sons do aplicativo:

P1 (Nível leve) - "Hoje ele jogou o ABC Autismo uns 10 minutos, escolheu de cara o ABC [Autismo]. Durante o jogo observei algumas reações dele como gritos e sorrisos, ele parece ficar feliz durante o uso".

P4 (Nível leve) - "O ABC do autismo é bem variado, tem fases diferentes, ela gosta muito desse aplicativo de montar o quebra-cabeça também”.

P5 (Nível leve) - "O ABC Autismo é o favorito dele, o jogo é completo e bem colorido como ele diz". 
P6 (Nível leve) - "No ABC [Autismo], ele me chama pra explicar dizendo 'mamãe é só arrastar, segurar e soltar' e mostrar as figurinhas que vai aparecendo, ele acha lindo porque é bastante colorido. Ele gosta muito do ABC Autismo".

P10 (Nível leve) - "O Jogo do ABC [Autismo], acho que é o favorito dele viu, ele fica jogando e sorrindo e me mostra as coisas e me explica, na fase 4 algumas palavras ele já completa como casa, planeta. É a fase que ele mais gosta, ele ama desafios".

\subsubsection{Jade Autismo}

Nove mães forneceram relatos sobre o uso do aplicativo Jade Autismo pelos seus filhos. Por meio da codificação aberta, foram criados os códigos: (i) Problemas com acessibilidade/interação, (ii), Irritação quando não consegue concluir os desafios e (iii) Recursos audiovisuais promovem boas experiências. A Figura 15 representa o esquema gráfico obtido a partir da codificação.

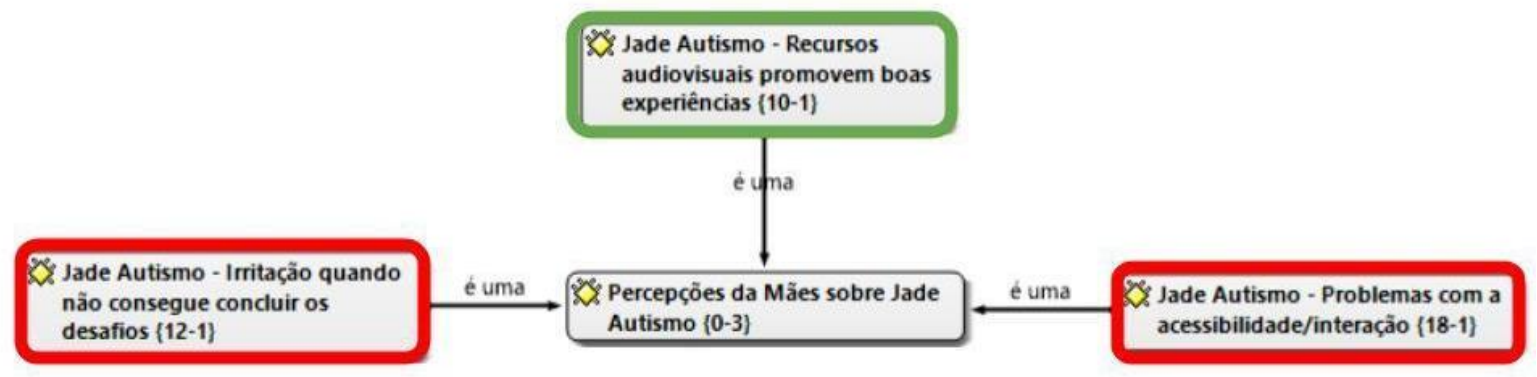

Figura 15: Codificação dos dados do aplicativo Jade Autismo.

Jade Autismo - Problemas com a acessibilidade/interação: indicaram que as crianças enfrentaram problemas com a acessibilidade/interação durante o uso do aplicativo educacional Jade Autismo como. Este código obteve um grau de fundamentação teórica igual a 18, indicando que foram obtidos diversos relatos que fundamentam o código:

P3 (Nível leve) - "O Jade [Autismo] ele jogou 5 minutos também, ele tem dificuldades para iniciar o jogo porque precisa colocar o nome do jogador e isso ainda é muito avançado pra ele".

P5 (Nível leve) - "O Jade autismo confunde muito ele nas fases e ainda tem aquele problema de quando começa o jogo ter que colocar o nome, é o que ele menos joga viu”.

P4 (Nível leve) - "No Jade Autismo tem uma categoria das cores para associar as [cores] de cima com as [cores] de baixo. Quando ela seleciona um quadrado com a [fruta] laranja, ai fica o fundo verde ela vai e clica no verde e erra. Isso a confunde e chora, não quer mais jogar". A Figura 16 ilustra a interação descrita por P4, a mistura de cores confunde de fundo com a cor do elemento, causou confusão na realização do desafio. 


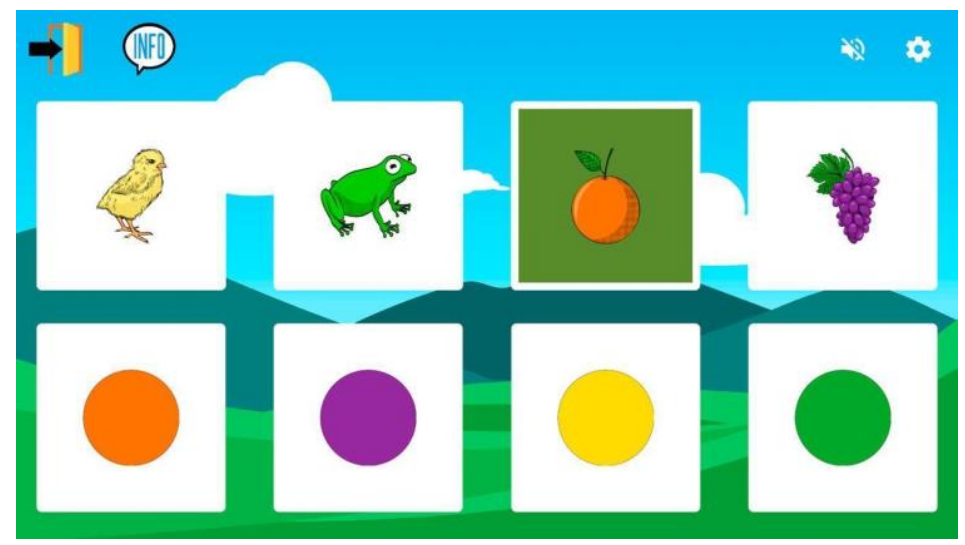

Figura 16: Desafios do aplicativo Jade Autismo

P7 (Nível leve) - "O Jade autismo, não sei se é um erro, mas quando ele clica na uva, a imagem fica verde ai ele clica na cor verde e aparece a mensagem de erro, ai depois eu entendi isso e tentei explicar que ele tem que olhar a cor da fruta ao invés da cor do quadro. Mas explicar isso para uma criança com autismo não é simples, é um desafio, mas expliquei e ele aprendeu." A Figura 17 ilustra que a cor de fundo verde é um padrão adotado pelo aplicativo para indicar o objeto selecionado.

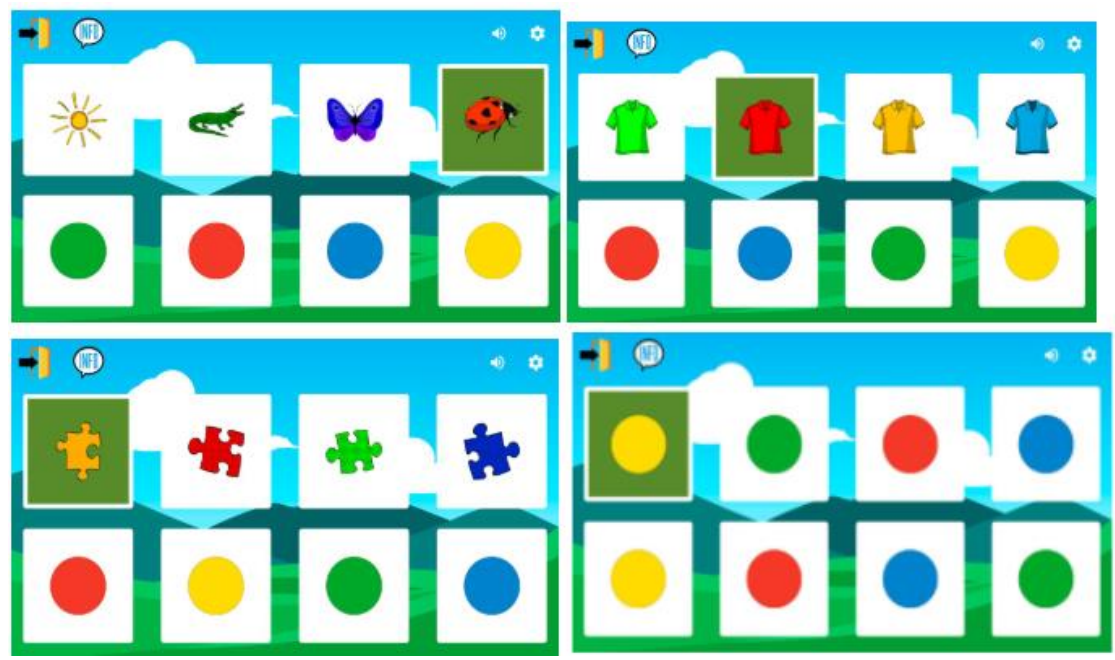

Figura 17: Exemplos de desafios da categoria de cores do aplicativo Jade Autismo

Jade Autismo - Recursos audiovisuais promovem boas experiências: indicam que o aplicativo promove boas experiências devido aos seus recursos audiovisuais:

P4 (Nível leve) - "[Com] o Jade [Autismo], ela tem mais dificuldade, ela gosta da fase dos animais porque tem o áudio com barulho dos animais e embaixo as figuras, ai ela gosta bastante. Fica dando play no som e sorrindo".

P8 (Nível leve) - “Aquele Jade Autismo ele só gosta da parte que tem um áudio para associar com o animal, ele quer pegar o celular e jogar sozinho”.

P10 (Nível leve) - "No Jade [Autismo], ele gosta da parte dos animais que tem o áudio para associar com a imagem de baixo, ele joga uns 10 minutos aí começa a ficar mais complexo para o nível dele e ele sai do jogo e começa a troca por outro jogo".

Na Figura 18, temos exemplos de desafios com recursos de áudio e imagem, conforme relatados pelos participantes. Esta diversidade de recursos proporcionou boas experiências às crianças. 


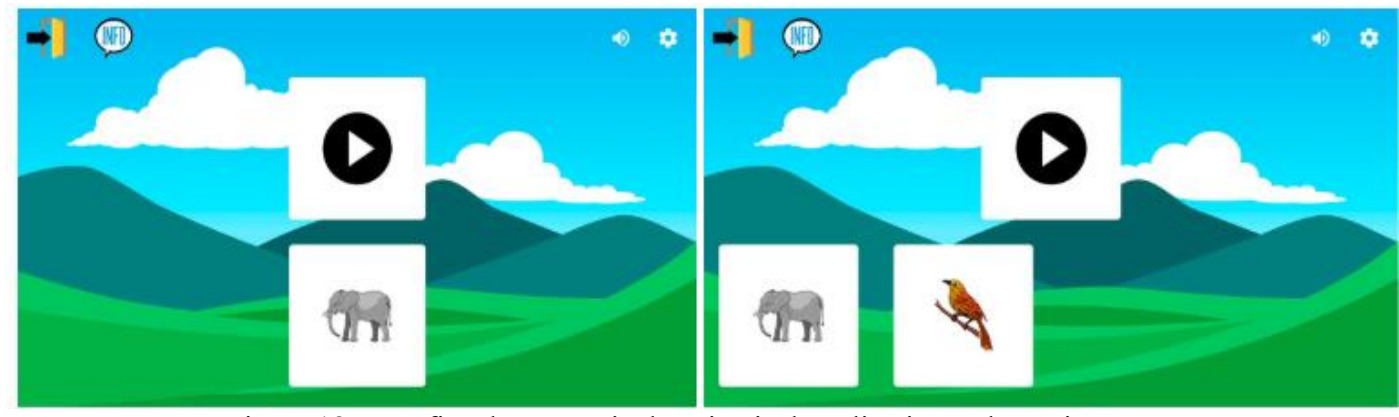

Figura 18: Desafios da categoria de animais do aplicativo Jade Autismo

Jade Autismo - Irritação quando não consegue concluir os desafios: indicam que as crianças demonstraram irritação ao não conseguir concluir os desafios do aplicativo Jade Autismo:

P1 (Nível leve) - "Depois jogamos o Jade autismo por 6 minutos e ele alterou o humor dele logo quando começou o jogo, porque precisa colocar um nome para começar a jogar e ele ainda não sabe colocar, ai ele ficou impaciente e gritou e depois não queria mais jogar, isso irritou muito ele". A Figura 19 ilustra as telas do aplicativo nas quais é solicitado um cadastro para começar a jogar. $\mathrm{O}$ usuário pode informar nome, gênero e data de nascimento ou e-mail e senha.

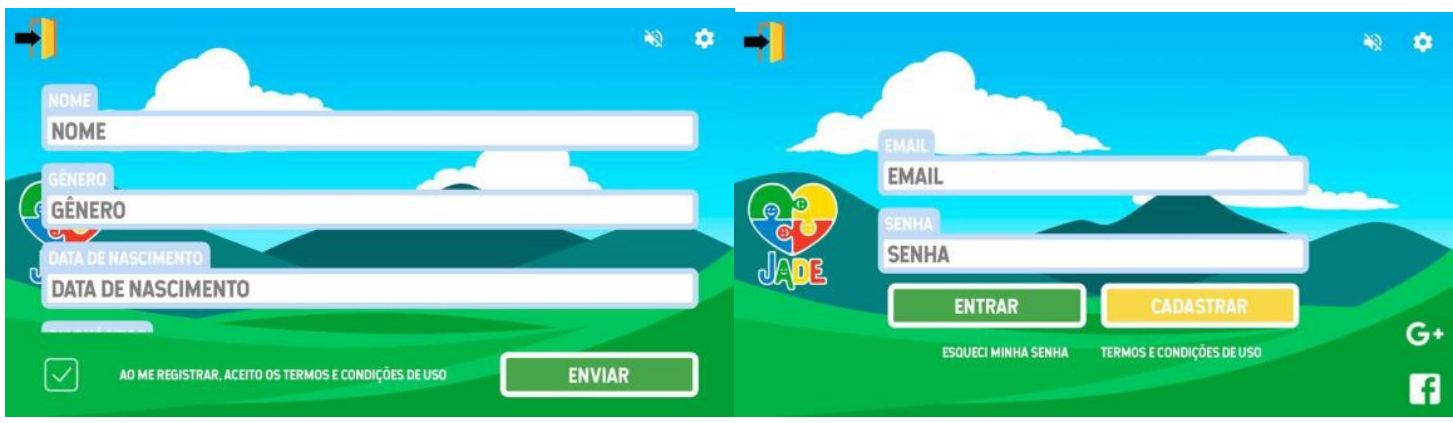

Figura 19: Tela inicial e tela de cadastro do aplicativo Jade Autismo.

P2 (Nível moderado) - "O humor dele muda quando ele erra alguma atividade no jogo Jade Autismo."

P7 (Nível leve) - "O Jade autismo ele gosta, mas tem dificuldades em ter que sempre selecionar a figura de cima e depois a de baixo, isso irrita ele e faz com que ele queira mudar o jogo".

\subsubsection{OTO (Olhar, Tocar, Ouvir)}

O aplicativo OTO foi experimentado por três crianças. Assim, três mães forneceram relatos sobre o uso do aplicativo OTO por seus filhos. Os seguintes códigos foram criados com base nos dados coletados sobre o aplicativo: (i) Auxilia na fala/educação, (ii) Recursos audiovisuais promovem boas experiências, (iii) Feedback positivo das mães e (iv) Falta de variedade nos desafios. A Figura 20 ilustra os resultados obtidos com a codificação. Vale ressaltar que este aplicativo foi o único para o qual foram obtidos relatos de feedback positivo das próprias mães sobre o seu uso. 


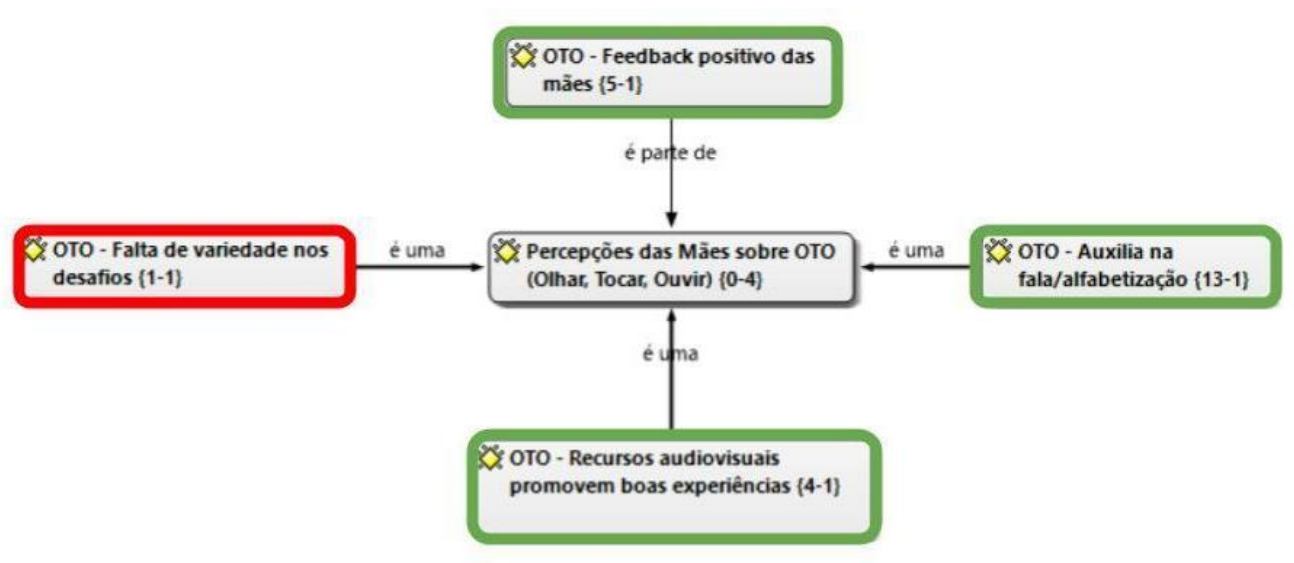

Figura 20: Codificação dos dados do aplicativo Jade Autismo.

OTO - Auxilia na fala/alfabetização: indicam que o aplicativo auxilia crianças autistas na fala/alfabetização:

P5 (Nível leve) - "[Ao utilizar] O jogo OTO, eu acompanho ele para poder ajudá-lo a falar. Ele já melhorou bastante”.

P6 (Nível leve) - "O jogo OTO estimulou bastante ele a falar mais, melhorando o desempenho dele na escola. Eu reduzo o som do celular e peço que ele diga qual letra é aquela [exibida] na tela e depois aumento [o som], deixando ele escutar se acertou ou errou a letra, muito bom".

OTO - Feedback positivo das mães: indicam um feedback positivo sobre o uso do aplicativo $O T O$ fornecido pelas mães:

P1 (Nível leve) - "Eu estou gostando de testar mais esse OTO porque ajuda muito na necessidade dele, está estimulando a fala dele [...] Ele sempre repete junto comigo, eu estou muito feliz".

P5 (Nível leve) - "Hoje ele pegou meu celular e já colocou no OTO. Ele ficou bem animado e foi mostrar para minha mãe e também mostrar que ele já conhece as letras do alfabeto. Minha mãe ficou contente. Ele passou mais de 20 minutos [usando o aplicativo] hoje, estou muito feliz de verdade".

OTO - Recursos audiovisuais promovem boas experiência: indicam que as cores e sons do aplicativo promovem boas experiências às crianças:

P1 (Nível leve) - "Já o OTO ele está gostando bastante as letras coloridas, o som que repete e depois mostra o animal. Ele fica todo contente".

P5 (Nível leve) - "No OTO, ele vai clicando nas letrinhas, mas ele já conhece todas as letras ele acha interessante porque aparece os animais e os animais emitem um som".

P6 (Nível leve) - "No OTO ele clica em todas as letras [...] às vezes ele volta para as letras dos animais que ele gosta só pra ouvir o som”.

OTO - Falta de variedades nos desafios: relatos de que o aplicativo apresenta poucas variedades nos desafios. Vale ressaltar que o OTO possui uma única interface de usuário, no qual são listadas letras. Isso justifica a limitação na variedade de opções do aplicativo.

P1 (Nível leve) - "[ele] não demonstra gostar muito porque o jogo é simples, não tem desafios como nos outros".

\subsubsection{Aprendendo com Biel e seus amigos}


Cinco mães forneceram relatos em relação ao uso do aplicativo Aprendendo com Biel e seus amigos por seus filhos. Com base na codificação, foram definidos os códigos: (i) Recursos variados promovem boas experiências e (ii) Falta de variedade nos desafios. A Figura 21 representa os resultados obtidos para o aplicativo Aprendendo com Biel e seus amigos.

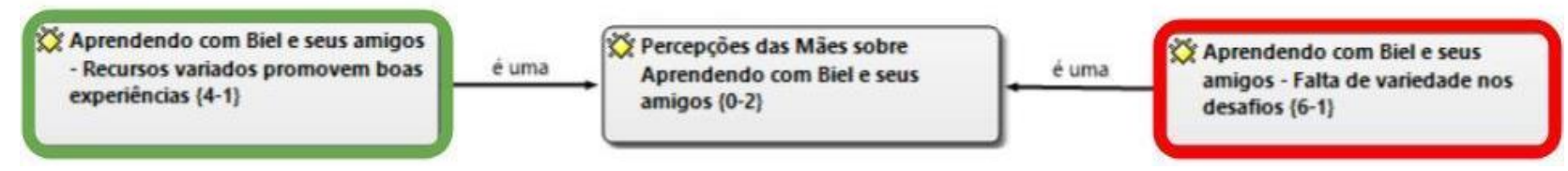

Figura 21: Codificação dos dados do aplicativo Aprendendo com Biel e seus amigos.

Aprendendo com Biel e seus Amigos - Recursos variados promovem boas experiências: apresentam os relatos das mães que indicaram a relação do uso dos aplicativos promover boas experiências em crianças autistas como, por exemplo, nos relatos de P4 e P8:

P4 (Nível leve) - "Ela pediu para colocar no jogo do Biel e seus amigos. Ela gosta porque ele tem várias opções de jogo".

P8 (Nível leve) - "O [aplicativo] aprendendo com Biel e seus amigos ele gosta porque tem várias opções no mesmo jogo, tem como arrastar, selecionar e associar. Ele gosta e mostra interesse em jogar sozinho”. A Figura 22 ilustra as opções de interação no jogo.

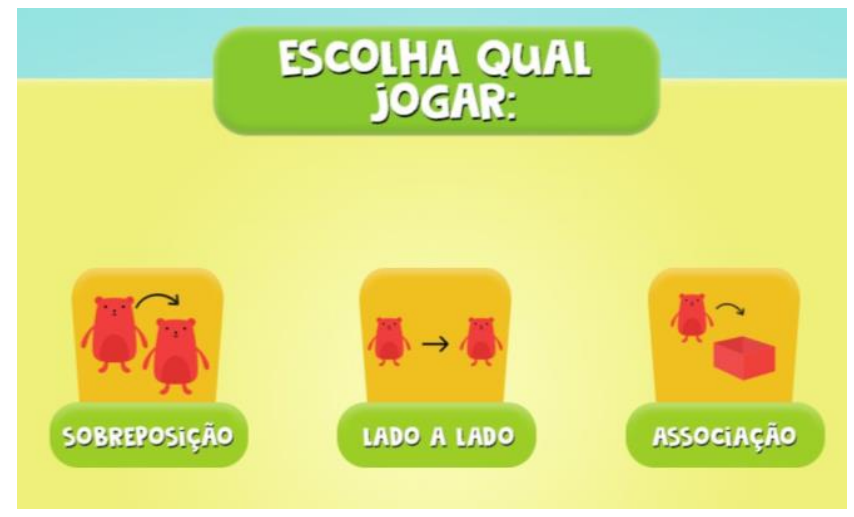

Figura 22: Exemplo de diferentes maneiras de jogar do aplicativo Aprendendo com Biel e seus amigos

Aprendendo com Biel e seus Amigos - Falta de variedades nos desafios: relatos de que o aplicativo Aprendendo com Biel e seus amigos apresenta poucas variedades nos desafios:

P7 (Nível leve) - "O Jogo do Biel [e seus amigos] ele acha bem parecido com o ABC [Autismo], porque são as opções de arrastar. Ele gosta mais do ABC [Autismo], pois ele é variado e tem sons, isso chama a atenção dele”.

P3 (Nível leve) - "É muita coisa repetida e simples, aquelas partes iniciais que é só arrastar umas vacas para o lado de acordo com as cores, isso ele faz muito rápido e sempre é o mesmo método, o que muda são os objetos, ai ele não gosta". A Figura 23 ilustra que os desafios do aplicativo seguem o mesmo padrão de interação, alterando os objetos. 


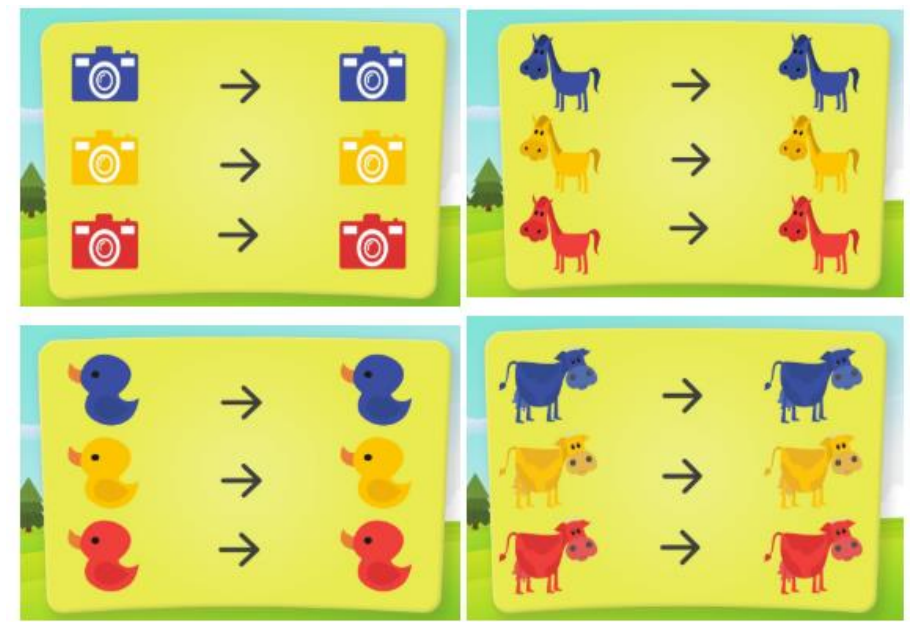

Figura 23: Desafios da categoria de animais com a maneira lado a lado do aplicativo Aprendendo com Biel e seus amigos

\section{Discussão}

Esta seção inicia com a discussão das experiências observadas e aspectos promovidos pelos jogos avaliados no estudo apresentado neste artigo. Em seguida, são discutidos os principais pontos da nossa contribuição com este trabalho.

Sobre as experiências positivas dos aplicativos avaliados, percebeu-se duas características em comum: o uso de cores e sons. Todas as crianças destacaram as cores na interface dos jogos como algo agradável. Em relação ao uso de sons nos jogos, apesar deste recurso ser citado em todos os jogos avaliados, foi observado que o jogo Jade Autismo possui apenas uma fase que promove associação de sons com figuras de animais, sendo a única fase indicada como experiência positiva. Também foi observado que houve a preferência de algumas crianças pelo jogo ABC Autismo devido à variedade de sons.

Ainda sobre as experiências positivas dos aplicativos avaliados, percebeu-se que o uso de opções de interação com no estilo quebra-cabeça e arrastar e soltar no jogo ABC Autismo promoveu boas experiências. O jogo Aprendendo com Biel e seus amigos também permite arrastar e soltar, possibilitando uma experiência positiva. Sobre tal jogo, P7 citou que o filho gosta deste jogo por possuir essa semelhança com o jogo ABC Autismo. A partir disso, é possível destacar o seguinte achado:

Diferentes recursos audiovisuais, como o uso de cores e sons, combinados com diferentes opções de interação, como quebra-cabeça e arrastar e soltar, podem causar experiências positivas para crianças autistas com jogos educacionais, contribuindo para o alcance dos objetivos educacionais propostos em tais jogos

Com base no achado descrito acima, em relação ao jogo ABC Autismo, por exemplo, percebeu-se que foi o único citado como 'preferido' e 'favorito' pelas crianças, como citou P5 e P10. Além disso, os diferentes recursos audiovisuais juntamente com as opções de interação podem ser a causa de obter o código Uso excessivo, observado apenas para o jogo ABC Autismo.

Sobre outros aspectos promovidos pelos jogos, observou-se que o jogo ABC Autismo promoveu a melhoria na coordenação motora das crianças. O jogo OTO auxiliou na fala e alfabetização das crianças, uma vez que as mães observaram uma evolução na fala de seus filhos. Com isso, identificou-se o achado descrito abaixo. Sobre tal achado, este pode direcionar a realização de novas pesquisas para compreender melhor tais aspectos. 
Jogos educacionais para crianças autistas, que adotam diferentes recursos audiovisuais combinados com diferentes opções de interação, podem promover o desenvolvimento de habilidades em crianças autistas, como a coordenação motora e comunicação

Em relação às experiências negativas, percebeu-se que quando alguma criança não consegue completar o desafio, isso ocasiona irritação. No jogo ABC Autismo, algumas crianças sentiram dificuldade em criar as palavras na Fase 4, citado por P1 e P10, visto que essas ainda não sabiam ler, tornando a fase mais complexa ao nível dos participantes deste estudo. Ao utilizar o Jade Autismo, algumas crianças se irritaram por não conseguirem iniciar o jogo devido à dificuldade de inserir o nome, como citou P1, P3 e P5. O feedback da mensagem de erro nesse jogo também irritou as crianças, como citou P4, P5 e P7. Dessa forma, é importante que tais jogos disponibilizem orientações para a realização de tais desafios. Com isso, foi identificado o seguinte achado:

Jogos educacionais para crianças autistas devem fornecer alternativas que apoiem a realização de desafios por diferentes perfis de usuários com o intuito de minimizar experiências negativas

A falta de variedade nos jogos também ocasionou algumas experiências negativas. Alguns participantes relataram que o jogo $A B C$ Autismo torna-se monótono e as crianças acabam desistindo do jogo, conforme citado por P1, P2 e P6. Isso também foi observado no jogo OTO, mas esse possui uma única interface de usuário, no qual são listadas letras, o que justifica tal limitação. No jogo Aprendendo com Biel e seus amigos, P3 e P7 citaram que este possui apenas a opção de arrastar e soltar para os mesmos objetivos, o que não agradou as crianças. Assim, a falta de variedade pode reduzir o interesse das crianças pelos aplicativos a longo prazo. Isso permitiu identificar o seguinte achado:

Jogos educacionais para crianças autistas devem possuir variedade de desafios para manter o interesse na realização dos objetivos educacionais

O uso dos diários proporcionou a identificação de achados interessantes em nossa pesquisa, os quais podem guiar educadores que tenham a intenção de utilizar jogos educacionais como apoio ao ensino de crianças autistas e desenvolvedores interessados no desenvolvimento deste tipo de jogo. Os resultados obtidos nesta pesquisa corroboram com pesquisas anteriores nas quais os pesquisadores concluíram que as tecnologias podem apoiar o processo de ensino de crianças autistas (Silva et al., 2019; Silva Neto et al., 2013) e contribuir na vida de uma criança autista na aquisição e desenvolvimento habilidades (Oliveira Neto et al., 2017).

\section{Conclusões e Trabalhos Futuros}

Esta pesquisa investigou a experiência de uso de aplicativos educacionais móveis por crianças autistas em seu cotidiano. Os aplicativos educacionais avaliados foram ABC Autismo, Jade Autismo, Aprendendo com Biel e seus amigos e OTO. A pesquisa foi conduzida com dez crianças autistas cujas mães participam de uma associação direcionada ao autismo e indicaram interesse em contribuir voluntariamente com a pesquisa. Para investigar a experiência de uso, a metodologia de diários de usuário foi adotada ao longo de duas semanas. As mães forneceram relatos de uso diários a partir da observação da interação de seus filhos com os aplicativos educacionais. Uma análise qualitativa por meio de procedimentos de codificação foi adotada pelas pesquisadoras visando identificar aspectos-chave da experiência de uso das crianças. 
Os resultados indicaram que todos os aplicativos educacionais promovem boas experiências devido aos seus recursos audiovisuais como cores, sons e imagens. Em contrapartida, os aplicativos ABC Autismo e Jade Autismo apresentaram problemas de acessibilidade e interação durante o uso pelas crianças. As crianças se engajaram no uso dos aplicativos ABC Autismo e Aprendendo com Biel e seus amigos, mas a pouca variedade de desafios dos aplicativos afetou negativamente a experiência. $\mathrm{O}$ aplicativo $O T O$ proporcionou melhorias na comunicação verbal das crianças, ocasionando relatos com feedback positivo das mães, que mostraram satisfação com o resultado obtido pelo uso do aplicativo.

Conduzir a pesquisa no ambiente natural das crianças permitiu a obtenção de dados reais da experiência de uso intermediada pelas mães. Acredita-se que tal ambiente pode ter proporcionado um maior engajamento das crianças, sem interferências bruscas em sua rotina e ambiente natural. O uso de diários forneceu dados relevantes sobre a experiência de uso, permitindo identificar diversos fatores que não seria possível identificar por meio de uma única sessão de teste.

Considerando que foram avaliados quatro aplicativos e a amostra de participantes é de um município específico, os resultados desta pesquisa não podem ser generalizados a todas as crianças autistas. A amostra não continha nenhum participante com autismo severo. Contudo, os resultados permitem identificar potenciais benefícios dos aplicativos educacionais avaliados, o que pode auxiliar pais, mães e profissionais interessados na escolha de tecnologias educacionais. Espera-se que esta pesquisa possa contribuir na adoção dos aplicativos educacionais para crianças autistas, na melhoria da qualidade dos aplicativos avaliados pelos desenvolvedores responsáveis e no direcionamento de novas pesquisas empíricas.

Como trabalhos futuros, pretende-se investigar se existem relatos de uso dos aplicativos educacionais identificados nesta pesquisa nas lojas de aplicativo. Caso existam, os relatos reportam problemas de acessibilidade ou impactos positivos no desenvolvimento dos usuários autistas? Acredita-se que analisar esses dados pode enriquecer a análise apresentada neste artigo e permitir uma maior abrangência e generalização dos resultados.

\section{Agradecimentos}

As autoras agradecem o apoio financeiro da Universidade Federal do Ceará (UFC) por meio da concessão de bolsas nas modalidades PIBITI e PREX, ao apoio financeiro da Fundação Cearense de Apoio ao Desenvolvimento Científico e Tecnológico (FUNCAP) por meio do processo BP40172-00228.01.00/20.

\section{Referências}

Aguiar, E., Pedreira, L. O., Gomes, V., \& Sarinho, V. (2018). Avaliando Jogos Digitais Educativos para Indivíduos Portadores do Transtorno do Espectro Autista. In Brazilian Symposium on Computers in Education (Simpósio Brasileiro de Informática na EducaçãoSBIE) (Vol. 29, No. 1, p. 1830). doi: 10.5753/cbie.sbie.2018.1830 [GS Search]

American Psychiatric Association. (2014). DSM-5: Manual diagnóstico e estatístico de transtornos mentais. Artmed Editora. [GS Search]

Barbosa, M. W. (2017). Uma análise do uso de grounded theory em engenharia de software. Revista Produção Online, 17(1), 26-48. doi: 10.14488/1676-1901.v17i1.2326 [GS Search] 
Brasil. (2012). Lei n ${ }^{0}$ 12.764, de 27 de dezembro de 2012. Institui a Política Nacional de Proteção dos Direitos da Pessoa com Transtorno do Espectro Autista. Disponível em: $<\underline{\text { http://www.planalto.gov.br/ccivil_03/_ato2011-2014/2012/lei/112764.htm> }}>$

Campanário, I. S. (2008). Espelho, espelho meu: a psicanálise e o tratamento precoce do autismo e outras psicopatologias graves. Ágalma.

Egido, S. V., Andreetti, T. C., \& dos Santos, L. M. (2018). Tecnologia educacional na sala de aula de matemática em uma turma com um aluno com TEA. Colóquio Luso-Brasileiro de Educação-COLBEDUCA, 3. [GS Search]

Farias, E. B., Silva, L. W., \& Cunha, M. X. (2014). ABC AUTISMO: Um aplicativo móvel para auxiliar na alfabetização de crianças com autismo baseado no Programa TEACCH. In Anais do X Simpósio Brasileiro de Sistemas de Informação (pp. 458-469). SBC. doi: $\underline{10.5753 / \mathrm{sbsi} .2014 .6136}$ [GS Search]

Fernandes, Freire, A. P., Fortes, R. P. M. Automatic Accessibility Evaluation of Dynamic Web Pages Generated Through XSTL. International Cross-Disciplinary Workshop on Web Accessibility. ACM International Conference Proceeding Series; V 88, pp 81-84, USA, 2005. doi: $\underline{10.1145 / 1061811.1061826}$ [GS Search]

Ferreira, W., Cordeiro, R., Aguiar, Y. P. C., Saraiva, J., Tardif, C., \& Galy, E. (2018). Panorama das Publicações Nacionais sobre Autismo, Educação e Tecnologia. In Brazilian Symposium on Computers in Education (Simpósio Brasileiro de Informática na Educação-SBIE) (Vol. 29, No. 1, p. 913). doi: 10.5753/cbie.sbie.2018.913 [GS Search]

Gadia, C. A., Tuchman, R., \& Rotta, N. T. (2004). Autismo e doenças invasivas de desenvolvimento. Jornal de pediatria, 80(2), 83-94. doi: 10.1590/S002175572004000300011 [GS Search]

Gonçalves, M. (2011). Alunos com Perturbações do espectro do Autismo: utilização do sistema PECS para promover o desenvolvimento comunicativo. 2011. $222 \mathrm{f}$ (Doctoral dissertation, Dissertação (Mestrado em Ciências da Educação) -Programa de Pós-Graduação em Ciências da Educação, Instituto Politécnico, Lisboa). [GS Search]

Gonçalves, R., Pessoa, C., Passos, O. M., \& de Amorim, R. (2019). Ferramentas Assistivas no Ensino e Aprendizagem de Crianças com Aspectro Autista: Um Mapeamento Sistemático. In Brazilian Symposium on Computers in Education (Simpósio Brasileiro de Informática na Educação-SBIE) (Vol. 30, No. 1, p. 1291). doi: 10.5753/cbie.sbie.2019.1291 [GS Search]

Hyldegård, J. (2006). Collaborative information behaviour-exploring Kuhlthau's Information Search Process model in a group-based educational setting. Information processing \& management, 42(1), 276-298. doi: 10.1016/j.ipm.2004.06.013 [GS Search]

Lazar, J., Feng, J. H., \& Hochheiser, H. (2017). Research methods in human-computer interaction. Morgan Kaufmann. [GS Search]

Mello, A. (2007). Autismo: guia prático. São Paulo: AMA. [GS Search]

Moita, F., Henrique, L., Candido, V., \& Medeiros, F. M. (2017). Design e desenvolvimento de um game assistivo para autistas. In Brazilian Symposium on Computers in Education (Simpósio Brasileiro de Informática na Educação-SBIE) (Vol. 28, No. 1, p. 1057). doi: $\underline{10.5753 / \text { cbie.sbie.2017.1057 [GS Search] }}$

Muller, M. (2014). Curiosity, creativity, and surprise as analytic tools: Grounded theory method. In Ways of Knowing in HCI (pp. 25-48). Springer, New York, NY. [GS Search]

Oliveira Neto, A., Rufino, H., Nakamoto, P., Palis, R., \& Beira, D. (2017). Cotidiano: um software para auxiliar crianças autistas em suas atividades diárias. In Brazilian Symposium on 
Computers in Education (Simpósio Brasileiro de Informática na Educação-SBIE) (Vol. 28, No. 1, p. 404). doi: 10.5753/cbie.sbie.2017.404 [GS Search]

Pantoja, J., Sousa, A., \& de Araújo Júnior, R. M. (2018). Alfa autista: uma aplicação mobile para o auxílio na alfabetização do autista através de método fônico. Um estudo de caso na APAEMarabá. In Brazilian Symposium on Computers in Education (Simpósio Brasileiro de Informática na Educação-SBIE) (Vol. 29, No. 1, p. 1873). doi: 10.5753/cbie.sbie.2018.1873 [GS Search]

Passerino, L. M. (2012). Comunicação alternativa, autismo e tecnologia: estudos de caso a partir do Scala. O professor e a educação inclusiva: formação, práticas e lugares. Salvador/BA: Editora da Universidade Federal da Bahia, 217-240. [GS Search]

Rodrigues, J., Abilhoa A. C. (2015) OTO: Um Aplicativo Android para Auxílio da Aprendizagem de Crianças Portadoras de Transtorno do Espectro Autista. Faculdade Guairacá. Guarapua. [GS Search]

Serra, D. (2010). Sobre a inclusão de alunos com autismo na escola regular. Quando o campo é quem escolhe a teoria. Revista de Psicologia, Fortaleza, v. 1, n. 2, p.163-176, jul. 2010. [GS $\underline{\text { Search }}$

Silva, M. D., Soares, A. C. B. \& Moura, I. C. (2019). Aplicação de Ferramentas Computacionais para o desenvolvimento do ensino de crianças com autismo: um Mapeamento Sistemático da Literatura. Revista Brasileira de Informática na Educação - RBIE, 27(3), 351-368. doi: 10.5753/RBIE.2019.27.03.351 [GS Search]

Silva Neto, O. P. D., Sousa, V. H. V., Batista, G. B., Santana, G. B. C. F., \& Junior, O. B. M. J. (2013). G-TEA: Uma ferramenta no auxílio da aprendizagem de crianças com Transtorno do Espectro Autista, baseada na metodologia ABA. SBC-Proceedings of SBGames. [GS $\underline{\text { Search }}]$

Sousa, F., Costa, E. \& Castro, T. (2012). WorldTour: Software para Suporte no Ensino de Crianças Autistas. Simpósio Brasileiro de Informática na Educação (SBIE), Rio de Janeiro. [GS Search]

Sousa, T. A., Ferreira, V. D., \& Marques, A. B. (2019). How do software technologies impact the daily of people with autism in Brazil: A survey. In Proceedings of the XV Brazilian Symposium on Information Systems (pp. 1-8). doi: 10.1145/3330204.3330274 [GS Search]

Strauss, A., Corbin, J. (2014). Basics of Qualitative Research: Techniques and Procedures for Developing Grounded Theory. 4th Edition. London: SAGE Publications. [GS Search]

Tenório, M. C. A., \& Vasconcelos, N. A. L. M. (2014). Autismo: a tecnologia como ferramenta assistiva ao processo de ensino e aprendizagem de uma criança dentro do espectro. En Congresso Internacional de Educação e Inclusão. [GS Search]

Zaccarelli, L. M., \& Godoy, A. S. (2010). Perspectivas do uso de diários nas pesquisas em organizações. Cadernos EBAPE. BR, 8(3), 550-563. [GS Search] 